\title{
Analytical model for predicting activation pressure and flow rate of pressure-compensating inline drip emitters and its use in low-pressure emitter design
}

\author{
Julia Sokol ${ }^{1}$ (D) . Jaya Narain ${ }^{1} \cdot$ Jeffrey Costello ${ }^{1} \cdot$ Tristan McLaurin $^{1} \cdot$ Dheekshita Kumar $^{1} \cdot$ Amos G. Winter $^{1}$
}

Received: 28 September 2020 / Accepted: 20 January 2022 / Published online: 14 February 2022

(c) The Author(s) 2022

\begin{abstract}
Drip irrigation has the potential to help farmers increase crop production with lower on-farm water consumption than flood or sprinkler irrigation; yet, its high costs keep it out of reach for many smallholder farmers, who make up about $20 \%$ of the world's population. Pressure-compensating (PC) drip emitters enable uniform water delivery to all crops in a field by regulating the emitter flow rate, but typically require high pumping pressures, contributing to high capital and operating costs for the pump and power system. Redesigning PC emitters for lower pressure operation could enable more energy-efficient and affordable drip systems. However, the current lack of published design theory for PC emitters hinders the development of emitters with desired hydraulic performance. To address this gap, we present an analytical, parametric model for the hydraulic behavior (i.e., the flow rate versus pressure curve) of inline PC emitters before the flow-regulating regime. We combine this model with a validated prototyping method to demonstrate its utility in the design of PC emitters with target activation pressures and flow rates, and demonstrate a sample design that achieves 38\% lower activation pressure than commercial emitters with similar flow rates. The proposed model sheds light on the parametric relationships between PC emitter geometry and performance. It may inform R\&D efforts in the irrigation industry and lead to improved emitter designs with low operating pressures, helping reduce drip system costs and increase access to drip irrigation among smallholder farmers.
\end{abstract}

\section{Introduction}

The use of drip irrigation in agriculture has been growing amidst concerns over water scarcity and insufficient crop yields (Foley et al. 2011). Hence, there is a growing need for engineering theory that can help design new drip system components and improve the performance of existing ones. This paper presents analytical theory describing the hydraulic performance of inline drip irrigation emitters and demonstrates its application to the design of improved lowpressure emitters that minimize pumping power.

Drip irrigation systems can enhance farmer food security in water- and food-scarce regions by mitigating weatherrelated risks and improving harvests (Postel et al. 2001; Burney et al. 2010; Woltering et al. 2011). In a number of

Julia Sokol

sokol@alum.mit.edu

1 Department of Mechanical Engineering, Massachusetts Institute of Technology, 77 Massachusetts Ave, Cambridge, MA, USA studies, well-managed and properly maintained drip systems have shown reductions of water use of $26-65 \%$ compared to flood or furrow irrigation, while attaining similar or higher crop yields (Bernstein and Francois 1973; Hanson et al. 1997; Cetin and Bilgel 2002; Narayanamoorthy 2004; Maisiri et al. 2005; Ibragimov et al. 2007; Ghamarnia et al. 2011). These water savings stem from reduced evaporation and deep percolation, as water is delivered through pipes and drip emitters directly to the roots of every crop in the field. However, drip systems require greater capital investment than flood or other surface irrigation systems. This contributes to low market penetration of drip systems relative to flood irrigation, particularly among smallholder farmers (ICID 2018; Namara et al. 2007). Therefore, reducing the cost of drip irrigation could allow more farmers to take advantage of its benefits, especially in locations where water is scarce or expensive (Srivastava et al. 2003).

Drip emitters play a critical role in drip irrigation systems, affecting system cost and performance. Emitters may be inline, i.e., bonded to the inside of the irrigation tubing at a predetermined spacing, or online, i.e., inserted manually into holes on the exterior of the tubing (Fig. 1a). They 


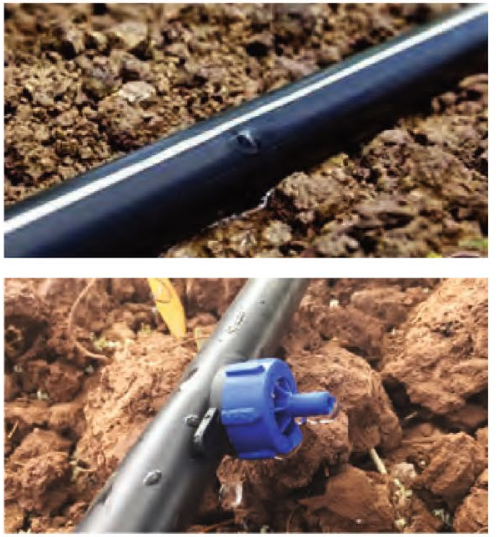

(a)

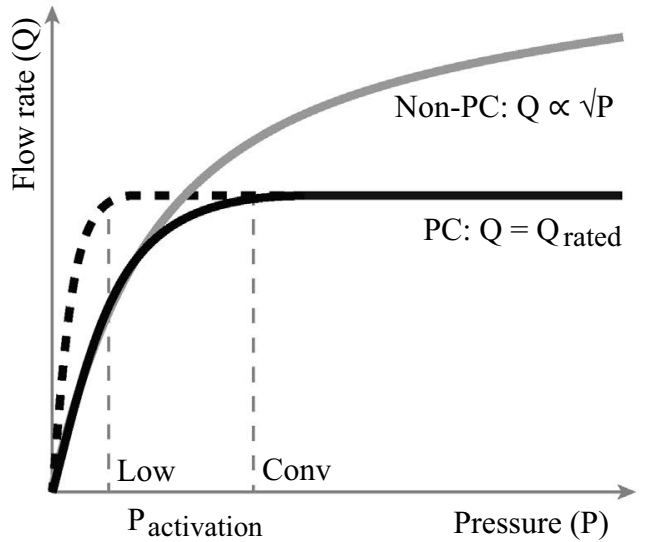

(b)

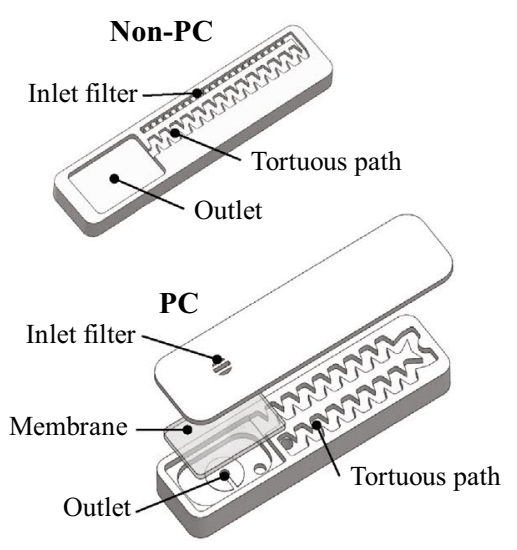

(c)
Fig. 1 Emitter types used in drip irrigation. a Tubing with an inlinestyle drip emitter bonded inside (top), and an online-style emitter installed outside (bottom). Water flows from the tubing through the emitter, then drips out near the roots of the crop. b Typical flowpressure curves for pressure-compensating (PC) (black) and nonpressure-compensating (non-PC) (gray) emitters. The dashed black

can be further separated into two categories: pressure-compensating (PC) and non-pressure compensating (non-PC) (Fig. 1b, c). PC emitters use a flexible membrane to regulate their flow rate to a constant value despite variations in water pressure, as long as the inlet pressure is above a minimum activation pressure (Fig. 1b). In contrast, non-PC emitters act as a fixed flow restriction, reducing the water flow rate to a trickle without regulating it, resulting in higher flow rates at higher pressures. By regulating flow, $\mathrm{PC}$ emitters can provide a more uniform water application to all of the crops in a field, even with uneven terrain, while also allowing for longer pipes and more freedom in the hydraulic network design (Phocaides 2007). However, the minimum pressure required for flow regulation to occur for commercial PC emitters is in the range of $40-100 \mathrm{kPa}(0.4-1.0 \mathrm{bar})$ (Jain Irrigation Systems Ltd 2019; Rainbird 2020; ChinaDrip 2020; Netafim 2020). With a surface water source (which is used for $62 \%$ of all irrigated land globally), this activation pressure can constitute up to half of the total system pressure drop that the pump needs to overcome (Shamshery and Winter 2018; FAO 2011). Thus, PC drippers provide the benefit of uniform water distribution, but can raise system costs above those with non-PC drippers.

Reducing the activation pressure of PC emitters (Fig. 1b) is one way to lower the pressure, pumping power, and capital cost of drip systems. For example, Shamshery and Winter (2018) found that changing the activation pressure of online PC emitters by $83 \%$, from 0.90 to 0.15 bar, could reduce the initial cost of an off-grid system for a tree farm with line shows the adjusted curve for a PC emitter with a low activation pressure compared to conventional (Conv), which can reduce the cost of a drip system. c Structure of typical PC and non-PC inline emitters. PC emitters consist of two plastic parts with a flexible membrane between them, which regulates the flow rate; non-PC emitters consist of one plastic part

a surface water source in India by $40 \%$. The cost savings result from the combination of a lower-power pump and a smaller-area solar array. This could facilitate the use of solar-powered pumps by reducing the size and cost of solar arrays, enabling the adoption of drip irrigation among farmers without electric grid access. Coupling solar pumps with drip irrigation, rather than with more water-intensive surface irrigation, can help limit the over-exploitation of groundwater resources (Burney et al. 2010), which may occur when expanding irrigation to previously rainfed or manually irrigated lands (Venot et al. 2017).

Parametric design theory could aid in developing a product line of inline PC drippers with minimal activation pressure over a range of flow rates. However, there is limited literature characterizing the physics of inline PC emitters parametrically. To the authors' knowledge, the design of PC emitters in industry occurs largely by trial-and-error and is heavily based on modifications of existing, previously proven commercial designs (Celik et al. 2011). Most academic research on inline emitters has focused on nonPC versions (Fig. 1c), utilizing CFD models (Wei et al. 2006; Dazhuang et al. 2007; Zhang et al. 2011a; Wang et al. 2012a), regression and machine learning models (Al-Amoud et al. 2014; Mattar and Al-Amoud 2015; Mattar et al. 2019; Philipova et al. 2011a, b; Zhang et al. 2011b), and digital particle image velocimetry experiments ( $\mathrm{Li}$ et al. 2008; Zhangzhong et al. 2015; Wu et al. 2013; Feng et al. 2018) to characterize flow through the tortuous path. While these works describe one component of a PC emitter, they do not 
account for the flow regulation function of the membrane (Fig. 1c). A smaller number of publications have characterized PC behavior specifically. Coupled CFD/FEA simulations have been used to explain how the interaction between the flexible membrane and the rigid emitter body creates flow-regulating behavior in online (Wang et al. 2012b) and inline (Tian 2013) emitters. However, these models were specific to the geometries analyzed and did not offer insights for generating new designs. In contrast to coupled numerical simulations, Shamshery et al. (2017) developed a fully analytical parametric model for PC online emitters and used it to optimize several designs for a low activation pressure (Shamshery and Winter 2018). One of these designs was subsequently manufactured and field tested on multiple farms, demonstrating an average $43 \%$ reduction in hydraulic energy (Sokol et al. 2019). Narain and Winter (2019) used a hybrid analytical-numerical approach to model PC inline emitters. Although this model matched the behavior of several commercial emitters, it was time-intensive to run and required multiple software tools, limiting its utility for early-stage parametric design of new inline geometries.

While numerical models are useful for detailed design, parametric analytical models are preferable in earlier stages, as they elucidate relationships between input parameters and resulting performance and allow engineers to quickly explore the design space. To the authors' knowledge, no publication has yet reported a method to quickly design inline PC drippers for desired hydraulic properties. To address this gap, this paper presents and validates a fully analytical, parametric model for a common inline PC emitter architecture, capable of determining the activation pressure and flow rate of the emitter. The model is fully described before activation pressure and offers scaling relationships between key parameters after activation pressure. This theory is combined with a validated prototyping method, and its utility is demonstrated by redesigning a commercial inline PC emitter to operate at 38\% lower pressure. The proposed analytical model and design procedure can be used by engineers in conjunction with more detailed numerical models of behavior after activation to design inline PC emitters with desired activation pressure and flow rates.

\section{Theoretical model of pressure-compensating inline drip emitters}

A PC inline emitter relies on a flexible silicone rubber membrane that deforms with pressure to regulate its flow rate. The water enters through a filter grid above the membrane at gauge pressure $P_{\text {in }}$, flows through a tortuous path where its pressure drops by $\Delta P_{\text {path }}$, then enters the chamber below the membrane at a reduced gauge pressure $P_{2}$ (Fig. 2a). From there, the water flows into the outlet, where it drops to atmospheric pressure as it exits the emitter and tubing. Most commercial designs use a membrane resting above a circular or rectangular chamber with the outlet at its center, and a small channel leading to the outlet through an embossed feature called the "lands" (Fig. 2a). The following analysis applies to flat or cylindrical emitter architectures with a tortuous path not covered by a membrane (Fig. 2a), which is used by several major irrigation companies, including Jain Irrigation, Ltd. (India) and The Toro Company (US).

The emitter has two operating regimes depending on the inlet pressure $P_{\text {in }}$. At zero inlet pressure, the emitter membrane is in its initial, undeformed state. At inlet pressures below activation pressure $\left(P_{\text {in }}<P_{\text {act }}\right)$, the membrane deforms without yet touching the lands, permitting radial flow into the outlet. At inlet pressure equal to activation pressure $\left(P_{\text {in }}=P_{\text {act }}\right)$, the membrane deforms enough to make contact with the lands and cover the outlet, forcing all flow to exit through the channel (Fig. 2c). With further increases in inlet pressure $\left(P_{\text {in }}>P_{\text {act }}\right)$, the flow resistance increases as the membrane covers more of the channel and shears into it, enabling flow regulation.

Considering steady-state flow at a given inlet pressure, the relationship between inlet pressure, $P_{\text {in }}$, and flow rate, $Q$, of a PC emitter in the regimes below and above activation can be represented as a circuit diagram (Fig. 2b) and expressed as Eqs. 1a, 1b with all pressures taken as gauge pressures relative to atmospheric. In the discussion below, $K$ refers to a modified pressure loss coefficient, $K=\frac{\Delta P}{Q^{2}}(\mathrm{~Pa}$ $\mathrm{h}^{2} / \mathrm{L}^{2}$ ), which incorporates both fluid velocity and area within the flow rate term. The flow rate is referred to in units of liters per hour $(\mathrm{L} / \mathrm{h})$, rather than the standard SI unit of $\mathrm{m}^{3}$ $/ \mathrm{s}$, following the convention used in the irrigation industry $\left(1 \mathrm{~L} / \mathrm{h}=2.778 \times 10^{-7} \mathrm{~m}^{3} / \mathrm{s}\right)$.

$P_{\text {in }}=\Delta P_{\text {path }}+P_{2}=Q^{2}\left(K_{\text {path }}+K_{\text {chamber }}\right)$ for $P_{\text {in }} \leq P_{\text {act }}$,

$P_{\text {in }}=\Delta P_{\text {path }}+P_{2}=Q^{2}\left(K_{\text {path }}+K_{\text {chamber }}+K_{\text {chan }}\right) \quad$ for $P_{\text {in }}>P_{\text {act }}$

Here, $K_{\text {path }}$ is the pressure loss coefficient in the tortuous path; $K_{\text {chamber }}$ is the pressure loss coefficient below the membrane in the PC chamber, which includes friction losses and the orifice effect at initial contact of the membrane with the lands; $K_{\text {chan }}$ is the additional pressure loss coefficient through the channel, which is zero when the covered channel length is zero (below and at activation) and an increasing function of $P_{\text {in }}$ after activation.

From Fig. 2b, the pressure drop from the inlet to the end of the tortuous path is equal to:

$\Delta P_{\text {path }}=P_{\text {in }}-P_{2}=Q^{2} K_{\text {path }}$,

and the gauge pressure below the membrane is: 


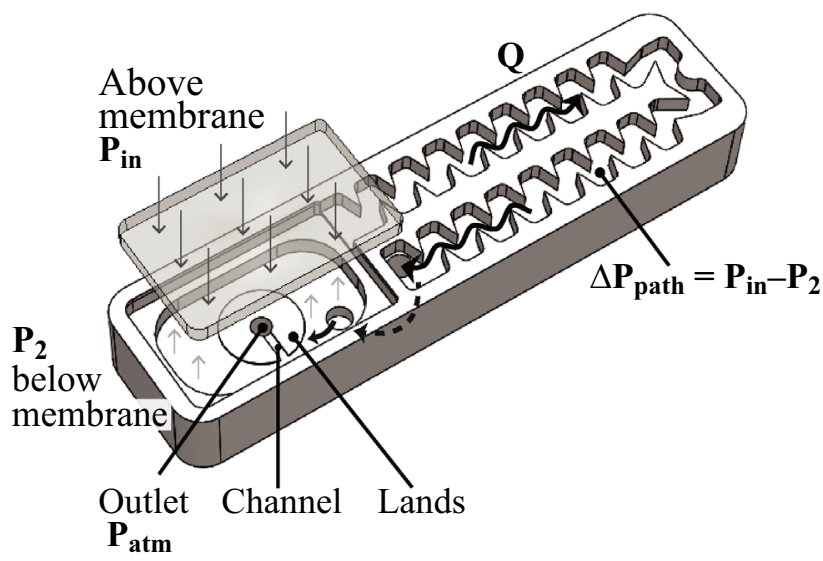

(a)

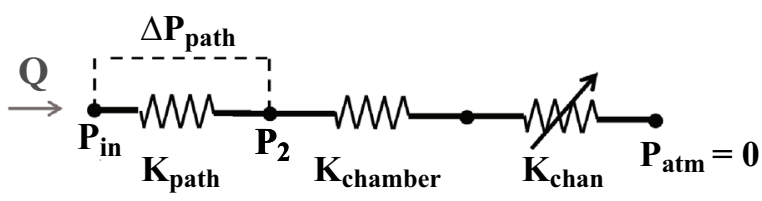

(b)

Fig. 2 Operating principle and structure of a typical inline PC emitter. a Water flows through an inline $\mathrm{PC}$ emitter at flow rate $Q$, entering the emitter above the membrane at pressure $P_{\text {in }}$, flowing down the tortuous path, through a passage on the bottom face (dashed arrow), entering chamber below the membrane at pressure $P_{2}$, and exiting through the outlet at $P_{\mathrm{atm}}$. b The hydraulic circuit representing flow resistances inside the dripper: the tortuous path, $K_{\text {path }}$, the membrane chamber, $K_{\text {chamber }}$, and the variable resistance in the channel, $K_{\text {chan }}$,

$P_{2}=Q^{2}\left(K_{\text {chamber }}+K_{\text {chan }}\right)$, with $K_{\text {chan }}=0$ for $P_{\text {in }} \leq P_{\text {act }}$.

Pressure loss coefficients in internal flows depend, in general, on the geometry of the flow path and the Reynold's number $\operatorname{Re}_{D_{\mathrm{h}}}$ (Edwards et al. 1985; Idelchik 1996). In most inline emitters, the tortuous path is bounded by rigid walls, so its geometry is fixed, and $K_{\text {path }}$ depends solely on $R e_{D_{\mathrm{h}}}$. (Some inline emitters have a membrane that covers the tortuous path in addition to the membrane chamber, forming one non-rigid wall for the labyrinth. In these designs, $K_{\text {path }}$ may also depend on the inlet pressure, with the dependence being most pronounced for low-stiffness membranes with wide tortuous paths. The present model is not applicable for architectures where membrane deformation into the tortuous path is significant.) On the other hand, the geometry of the flow path through the membrane chamber and channel varies with the membrane deformation, which, in turn, depends on the pressure difference across its thickness. Therefore, in the most general case, the pressure field in the fluid affects the
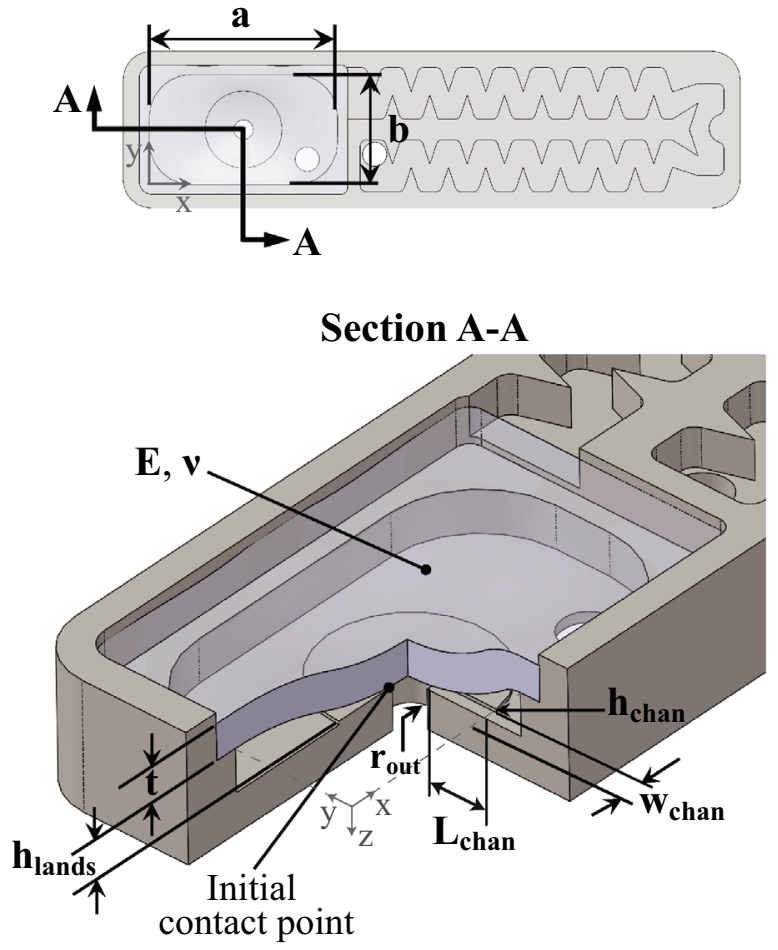

(c)

which increases with pressure above activation to regulate the flow rate, $Q$. c Detailed section view of the membrane chamber (with side lengths $a$ and $b$ ) of a PC inline emitter, drawn to scale based on one commercial emitter model. The membrane (with thickness $t$, Young's modulus $E$, Poisson's ratio $v$, and edges resting at distance $h_{\text {lands }}$ from the lands) is shown at activation pressure, as it first touches the lands around the outlet (with radius $r_{\text {out }}$ )

deformation of the membrane, and the values of $K_{\text {chamber }}$ and $K_{\text {chan }}$ require the simultaneous solution of the coupled fluid and solid equations until convergence (Narain and Winter 2019; Wei 2013). However, the following sections justify several simplifications that lead to analytical, closed-form expressions for the activation pressure and flow rate for a given emitter geometry.

\section{Analytical model of operation below activation pressure}

Two critical operating characteristics of the drip emitteractivation pressure and flow rate-can be determined using Eq. 1a in the regime before activation, $P_{\text {in }} \leq P_{\text {act }}$. The flow resistance begins to increase significantly when the membrane contacts the lands and blocks off the radial flow to the outlet, causing the flattening of the flow rate curve (Fig. 1b). Hence, the activation pressure, $P_{\text {act }}$, can be defined as the minimum inlet pressure at which the membrane contacts the lands. The activation flow rate, $Q_{\text {act }}$, is the flow rate at the 
activation pressure, which can be computed by plugging in $P_{\text {in }}=P_{\text {act }}$ into Eq. 1a and re-arranging to form Eq. 4:

$Q_{\text {act }}=Q\left(P_{\text {act }}\right)=\left(\frac{P_{\text {act }}}{K_{\text {path }}+K_{\text {chamber }}}\right)^{1 / 2}$.

$P_{\text {act }}$ and $Q_{\text {act }}$ can be determined by linking Eqs. 1a and 4 to the membrane's shape at activation. The membrane deflection, $\delta_{\text {mem }}(x, y)$, is governed by the fluid pressure field acting on it from above $\left(P_{\text {in }}\right)$ and below $\left(P_{2}\right)$, its geometry (length $a$, width $b$, thickness $t$ ), and material properties (Young's modulus $E$, Poisson's ratio $v$ ) (Fig. 2c). Thus, membrane deflection at any inlet pressure $P_{\text {in }}$ can be expressed as a function of these variables, $\delta_{\mathrm{mem}}\left(x, y, P_{\mathrm{in}}, P_{2}, a, b, D\right)$, where $D=\frac{E t^{3}}{12\left(1-v^{2}\right)}$ is the flexural modulus, which combines material properties with the thickness, and the boundary conditions dictate the choice of model (Ventsel and Krauthammer 2001). At $P_{\text {in }}=P_{\text {act }}$, the maximum deflection of the bottom surface of the membrane at any coordinates above the lands is limited to a distance $h_{\text {lands }}$ (Fig. 2c). This constraint on membrane deflection is used with the following assumptions-supported by experiments and prior literature- to derive an analytical solution for $P_{\text {act }}$ and $Q_{\text {act }}$ for typical inline dripper geometries.

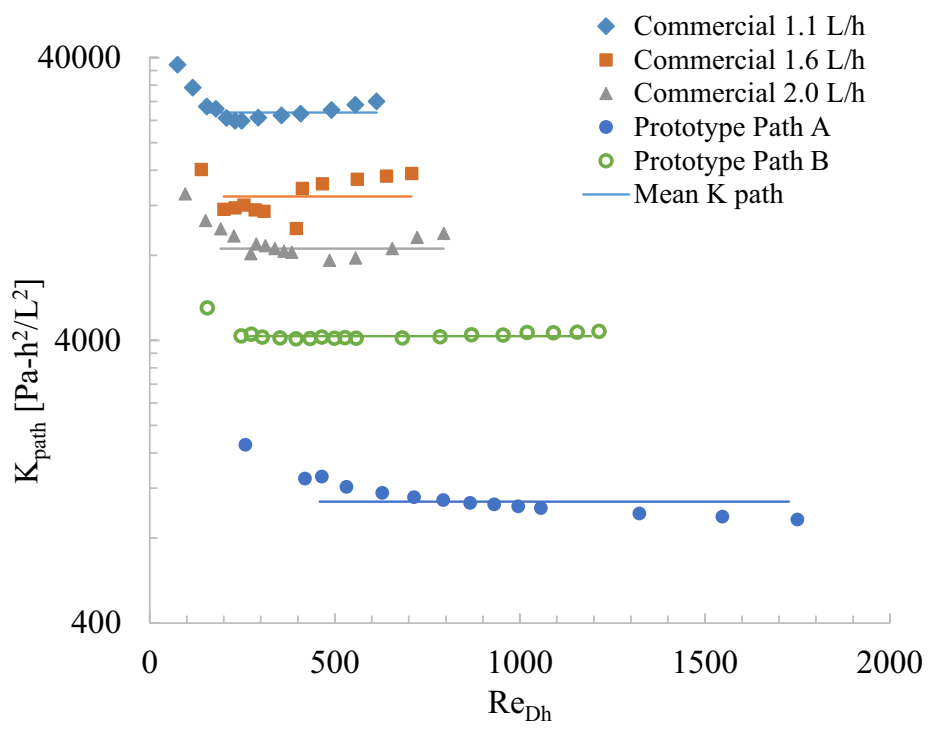

(a)

Fig. 3 Experimental evidence justifying the assumptions used to derive the analytical model; detailed methods for both experiments are included in the Appendix. a Plots of measured $K_{\text {path }}=\Delta P / Q^{2}$ versus $R e_{D_{b}}$ for five different tortuous path geometries from three commercial emitters and two machined prototypes show that $K_{\text {path }}$ can be treated as nearly constant above $R e_{D_{\mathrm{h}}} \approx 150-450$, depending on geometry. The plotted ranges correspond to inlet pressures of 2-100 kPa (0.02-1.0 bar), except for Prototype Path A, where the maximum pressure was $50 \mathrm{kPa}(0.5 \mathrm{bar})$, because higher pressures caused flow rates that exceeded the sensor range in this low-resistance
The first assumption is that $K_{\text {path }}$ is nearly constant with $R e_{D_{\mathrm{h}}}$ in the flow rate range relevant for inline drippers, due to sharp corners in the tortuous path that create vortices and induce turbulent behavior. Flow in tortuous paths has been characterized by multiple authors as having a lower onset of turbulence than expected from a straight channel, with transitional $R e_{D_{\mathrm{h}}}$ in the range 250-500 (Zhang et al. 2011a; Zhao et al. 2009; Al-Muhammad et al. 2016; Nishimura et al. 1983; Al-Muhammad et al. 2018). Above these values, the pressure loss coefficient has no dependence on $R e_{D_{\mathrm{h}}}$, analogous to turbulent flow in rough channels. Because each cited paper is based on a specific path geometry and choice of length scale for $R e_{D_{\mathrm{h}}}$, the five different tortuous paths used in this study were tested experimentally to validate this assumption and the applicable $R e_{D_{\mathrm{h}}}$ range. Detailed dimensions of the five tested tortuous paths and the experimental procedure for the $K_{\text {path }}$ measurement can be found in the Appendix, "Experimental measurements of tortuous path resistance". The five tortuous path geometries showed nearly constant $K_{\text {path }}$ above $R e_{D_{\mathrm{h}}} \approx 150-420$, which corresponded to inlet pressures between 2-4 $\mathrm{kPa}(0.02-0.04 \mathrm{bar})$, depending on path geometry (Fig. $3 \mathrm{a}$ ). Above these $R e_{D_{\mathrm{h}}}$ values, i.e., for measurements above $5 \mathrm{kPa}$ ( $0.05 \mathrm{bar})$, the mean $K_{\text {path }}$ and standard deviations of $K_{\text {path }}$ were calculated. The standard
2000

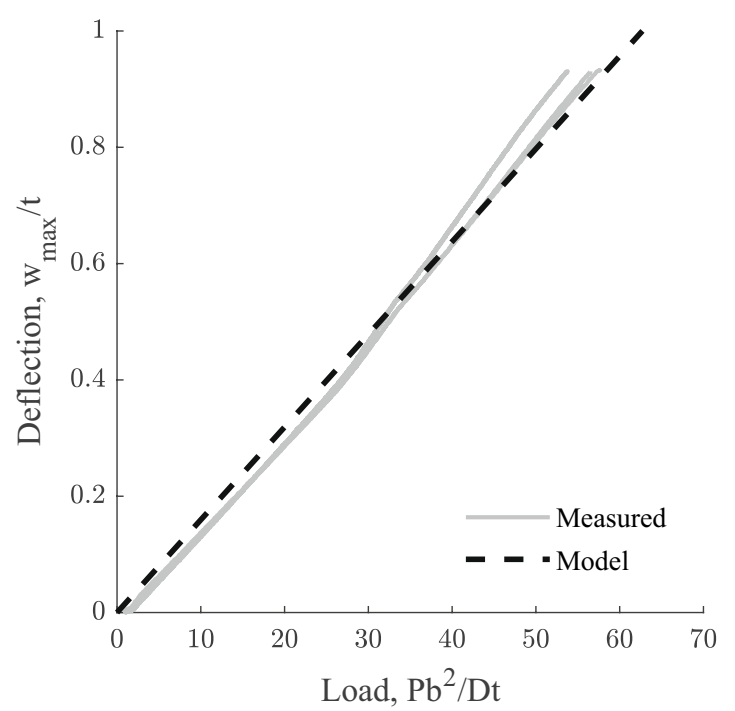

(b)

path. The mean $K_{\text {path }}$ values were calculated based on all inlet pressures above $5 \mathrm{kPa}(0.05$ bar). b Plot of measured maximum membrane deflection versus a concentrated load applied at the center of the membrane. Experimental deflection for one membrane at three different loading speeds $(0.1,0.25$, and $0.5 \mathrm{~mm} / \mathrm{s})$ is plotted in gray; the deflection is approximately linear with load. The dashed line shows the modeled deflection for this membrane using the Kirchhoff thin plate model with Young's modulus $(E=2.13 \pm 0.15 \mathrm{MPa})$ fitted to experimental data for three membranes 
deviations of measured values were within $10 \%$ of each mean $K_{\text {path }}$, except for the path from the $1.6 \mathrm{~L} / \mathrm{h}$ commercial emitter, where the standard deviation reached $15 \%$ of the mean. These variations are incorporated into the uncertainty of the present model, while $K_{\text {path }}$ is treated as constant equal to the measured mean. The variation of $K_{\text {path }}$ in the low-Re regime is not incorporated into the model, as it was observed to only affect a small portion of the operating pressure range and have minimal impact on the modeled results, while requiring a more complex iterative calculation procedure.

The second assumption is that the resistance of the membrane chamber, $K_{\text {chamber }}$, can also be treated as a constant before activation. $K_{\text {chamber }}$ comprises minor losses and friction losses in the flow between the entry to the membrane chamber and the outlet. While the bending of the membrane before activation has some effect on $K_{\text {chamber }}$, the cross-sectional flow area below the membrane is large enough for both the magnitude and the variation in $K_{\text {chamber }}$ to be negligible compared to the tortuous path resistance, $K_{\text {path }}$, in series with $K_{\text {chamber }}$ (Fig. 2b). Experiments show that the magnitude of $K_{\text {chamber }}$ is below $11 \%$ of $K_{\text {path }}$ for all commercial drippers tested (Table 1); $K_{\text {chamber }}$ increases to $\sim 30 \%$ of $K_{\text {path }}$ only for a custom-made tortuous path with very low resistance. Therefore, $K_{\text {chamber }}$ is approximated as constant to develop the analytical model of commercial emitters, but this assumption is expected to lead to greater errors for emitters with very low $K_{\text {path }}$, as discussed further in "Results of model validation".

membranes, and that Kirchhoff plate theory with Young's modulus $E=2.13 \pm 0.15 \mathrm{MPa}$ matched experimental membrane deflection in bending (Fig. 3b). Hence, linear thin plate theory is suitable for modeling membrane deflection before activation.

Membrane deflection can be calculated assuming the pressure is approximately uniform with magnitude $P_{1}$ above the membrane and at magnitude $P_{2}$ below it, except above the outlet, where the pressure is atmospheric (Narain and Winter 2019). Hence, the net loading is a uniform pressure $P_{\text {in }}-P_{2}$ over the full membrane area, plus an additional patch load over the outlet with pressure $P_{2}$ (Fig. 2a). Given that the outlet area, $\pi r_{\text {out }}^{2}$, is small compared to the full membrane area, $a b\left(\frac{\pi r_{\text {out }}^{2}}{a b}<0.02\right.$ for all emitters in this study), the patch load can be approximated as a concentrated load of magnitude $P_{2} \pi r_{\text {out }}^{2}$, acting in the same direction as the membrane deflection (towards the lands). Using the Navier double-series solution with simply supported boundary conditions (Ventsel and Krauthammer 2001) and the coordinate system shown in Fig. 2c, the membrane deflection under a uniform distributed load, $\delta_{\text {unif }}$, and under a concentrated load at the center, $\delta_{\text {conc }}$, is:

$$
\delta_{\text {unif }}(x, y)=\frac{16\left(P_{\text {in }}-P_{2}\right)}{\pi^{6} D} \sum_{m=1}^{\infty} \sum_{n=1}^{\infty} \frac{\sin \left(\frac{m \pi x}{a}\right) \sin \left(\frac{n \pi y}{b}\right)}{m n\left(\frac{m^{2}}{a^{2}}+\frac{n^{2}}{b^{2}}\right)^{2}},
$$

$\delta_{\text {conc }}(x, y)=\frac{4\left(P_{2} \pi r_{\text {out }}^{2}\right)}{\pi^{4} D a b} \sum_{m=1}^{\infty} \sum_{n=1}^{\infty} \frac{\sin \left(\frac{m \pi}{2}\right) \sin \left(\frac{n \pi}{2}\right) \sin \left(\frac{m \pi x}{a}\right) \sin \left(\frac{n \pi y}{b}\right)}{\left(\frac{m^{2}}{a^{2}}+\frac{n^{2}}{b^{2}}\right)^{2}}$,

The third assumption is that membrane deflection is linear with load before activation and can be modeled via superposition of multiple loads. The linearity of deflection with load is generally valid for thin $\left(\frac{t}{L} \lesssim 0.1\right.$, where $t$ is the thickness and $L$ is the characteristic side length) and moderately thick $\left(0.1 \lesssim \frac{t}{L} \lesssim 0.2\right)$ plates undergoing small deflection $\left(\frac{\delta_{\max }}{t} \lesssim 1\right)$, according to Kirchhoff and Mindlin plate theories, respectively (Szilard 2003). The membranes of commercial drippers used in this study have $\frac{t}{L} \sim 0.13-0.15$ (based on average side length) and $\frac{\delta_{\max }}{t} \sim 0.54-0.92$ at activation. As these ranges are borderline for several criteria, flexural experiments were conducted on silicone membranes of commercial emitters to validate this assumption and choice of plate model. Collected data confirmed that linearity with load was satisfied in the expected deflection range of the where $D$ is the flexural modulus. The overall membrane deflection can be found through their superposition (Ventsel and Krauthammer 2001):

$\delta_{\text {mem }}(x, y)=\delta_{\text {unif }}(x, y)+\delta_{\text {conc }}(x, y)$.

Combining Eq. 7 with the limit on membrane deflection at its first contact with the lands provides a closed-form expression for $P_{\text {act }}$. The maximum membrane deflection occurs at its center; therefore, its first contact with the lands occurs at the outlet radius, located a distance $h_{\text {lands }}$ from the undeformed membrane position (Fig. 2c). Plugging in the coordinates of an initial contact point on the outlet radius and the membrane's long axis of symmetry (Fig. 2c), $\left(x_{c}, y_{c}\right)=\left(\frac{a}{2}+r_{\text {out }}, \frac{b}{2}\right)$, into Eq. 7 and setting the deflection at that point equal to $h_{\text {lands }}$ at $P_{\text {in }}=P_{\text {act }}$ yields: 


$$
\begin{aligned}
h_{\text {lands }}= & \delta_{\text {mem }}\left(\frac{a}{2}+r_{\text {out }}, \frac{b}{2}\right) \\
= & \delta_{\text {unif }}\left(\frac{a}{2}+r_{\text {out }}, \frac{b}{2}\right)+\delta_{\text {conc }}\left(\frac{a}{2}+r_{\text {out }} \frac{b}{2}\right) \\
= & \frac{16\left(P_{\text {in }}-P_{2}\right)}{\pi^{6} D} \sum_{m=1}^{\infty} \sum_{n=1}^{\infty} \frac{\sin \left(\frac{m \pi}{2}+\frac{m \pi r_{\text {out }}}{a}\right) \sin \left(\frac{n \pi}{2}\right)}{m n\left(\frac{m^{2}}{a^{2}}+\frac{n^{2}}{b^{2}}\right)^{2}} \\
& +\frac{4\left(P_{2} \pi r_{\text {out }}^{2}\right)}{\pi^{4} D a b} \sum_{m=1}^{\infty} \sum_{n=1}^{\infty} \frac{\sin \left(\frac{m \pi}{2}\right) \sin \left(\frac{n \pi}{2}\right) \sin \left(\frac{m \pi}{2}+\frac{m \pi r_{\text {out }}}{a}\right) \sin \left(\frac{n \pi}{2}\right)}{\left(\frac{m^{2}}{a^{2}}+\frac{n^{2}}{b^{2}}\right)^{2}} .
\end{aligned}
$$

This can be expressed more concisely by combing all terms of the infinite series (which depend solely on the membrane side lengths and the outlet radius) and the numerical coefficients into constants $\alpha_{1}$ and $\alpha_{2}$ :

$h_{\text {lands }}=\alpha_{1} \frac{P_{\mathrm{act}}-P_{2}}{D}+\alpha_{2} \frac{r_{\mathrm{out}}^{2} P_{2}}{a b D}$.

The constants $\alpha_{1}, \alpha_{2}$ can be calculated by summing the full infinite series or the first few terms of each. Due to the rapid convergence of both series, summing the first nine terms is sufficient to converge to within $2.5 \%$ of the exact solution (Ventsel and Krauthammer 2001).

Solving Eq. 9 for $P_{\text {act }}$, substituting expressions for pressures $P_{\text {act }}$ and $P_{2}$ in terms of flow rate and resistances (Eqs. 2 and 3), and using Eq. 4 to relate $P_{\text {act }}$ to $Q_{\text {act }}$, results in the following expressions:

$P_{\text {act }}=\frac{D h_{\text {lands }}\left(K_{\text {path }}+K_{\text {chamber }}\right)}{\alpha_{1} K_{\text {path }}+\alpha_{2} K_{\text {chamber }} \frac{r_{\text {out }}^{2}}{a b}}$,

$Q_{\mathrm{act}}=\left(\frac{D h_{\text {lands }}}{\alpha_{1} K_{\mathrm{path}}+\alpha_{2} K_{\text {chamber }} \frac{r_{\text {out }}^{2}}{a b}}\right)^{1 / 2}$.

Equations 10 and 11 enable the direct computation of $P_{\text {act }}$ and $Q_{\text {act }}$ with input parameters of dimensions, material properties, and resistances, all of which can be estimated or measured. The geometric inputs and material properties can be measured directly. The resistances $K_{\text {path }}$ and $K_{\text {chamber }}$ can be determined for specific geometries by experiment or through CFD simulations. The full $Q$ versus $P_{\text {in }}$ curve of emitter hydraulic behavior before activation can be modeled using Eq. 1a up to the limit $P_{\text {in }}=P_{\text {act }}$ (Eq. 10). This analytical model provides physical intuition on how input parameters affect PC emitter performance, which is missing in published literature, and enables quick sensitivity analyses or optimizations for desired emitter flow rates and activation pressures.

\section{Analytical scaling for operation above activation pressure}

Although detailed modeling of the regime above activation requires numerical simulation, Eq. $1 \mathrm{~b}$ for $P_{\text {in }}>P_{\text {act }}$ can be used to derive the scaling of $K_{\text {chan }}$ with pressure needed for ideal flow regulation, i.e., to maintain $Q\left(P_{\text {in }}\right)=Q_{\text {act }}$ as $P_{\text {in }}$ increases above $P_{\text {act }}$. Substituting the target constant value $Q_{\text {act }}$ into Eq. $1 \mathrm{~b}$ provides the target $K_{\text {chan }}$ as a function of $P_{\text {in }}$ :

$$
\begin{aligned}
& P_{\text {in }}=Q_{\text {act }}^{2}\left(K_{\text {path }}+K_{\text {chamber }}+K_{\text {chan }}\left(P_{\text {in }}\right)\right) \\
&=Q_{\text {act }}^{2}\left(K_{\text {path }}+K_{\text {chamber }}\right)+Q_{\text {act }}^{2} K_{\text {chan }}\left(P_{\text {in }}\right) \\
&=P_{\text {act }}+Q_{\text {act }}^{2} K_{\text {chan }}\left(P_{\text {in }}\right), \\
& K_{\text {chan }}\left(P_{\text {in }}\right)=\frac{P_{\text {in }}-P_{\text {act }}}{Q_{\text {act }}^{2}} .
\end{aligned}
$$

Hence, to maintain a constant flow rate $Q_{\text {act }}$ above activation, the flow resistance in the channel must increase linearly with inlet pressure and be inversely proportional to the square of the activation flow rate. Emitter designers can use this expression as a guide to refine features that affect the flow rate after activation, such as the width and depth of the channel through the lands (Fig. 2c). Detailed models for fluid-structure interaction after activation (e.g., found in Narain and Winter 2019; Wei 2013) can be employed in conjunction with the current analytical model to adjust the features below the membrane after the main geometry has been selected. 


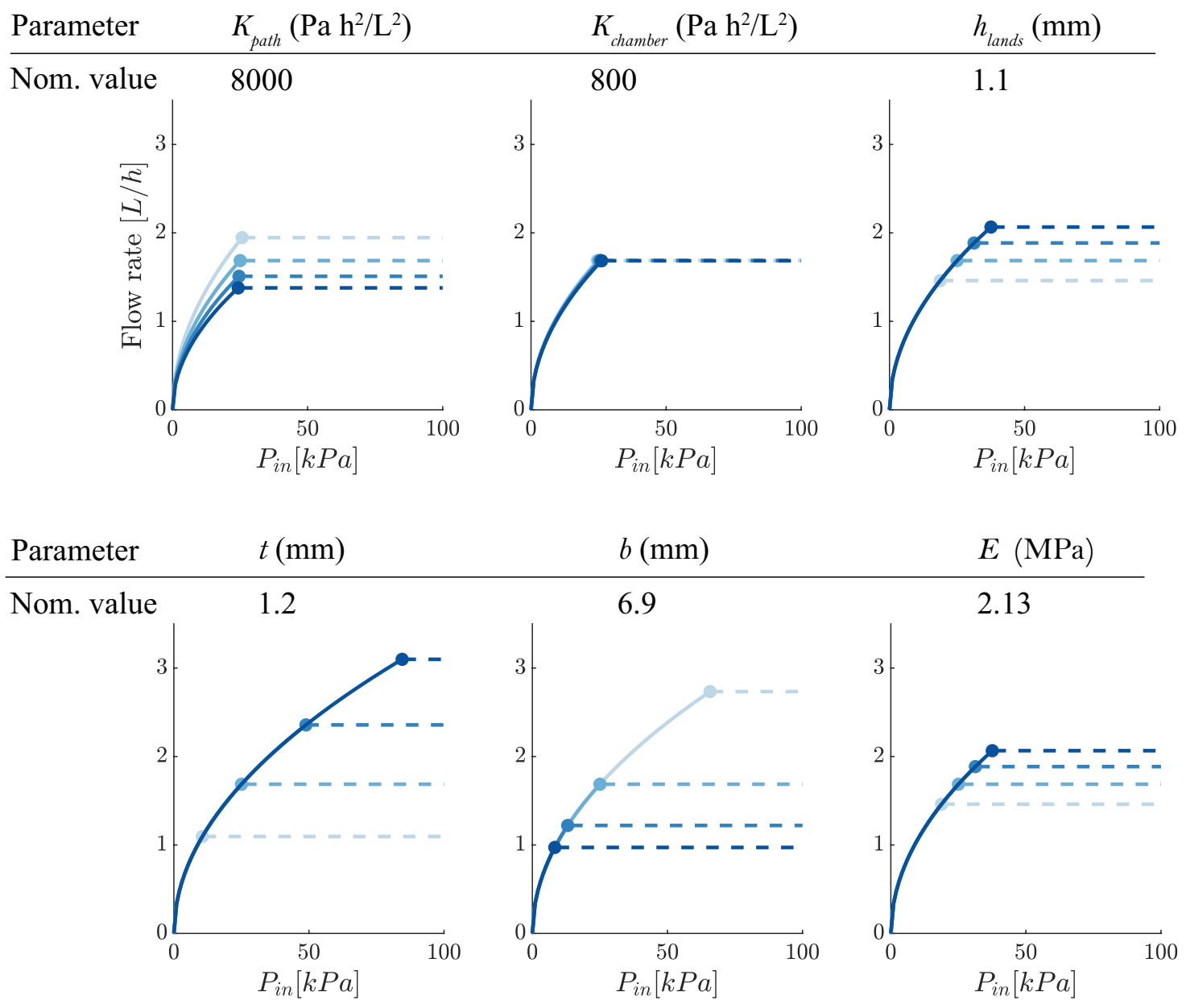

Fig. 4 Modeled sensitivity of emitter activation pressure and flow rate to changes in input parameters, including flow resistances, $K_{\text {path }}$ and $K_{\text {chamber }}$, lands to membrane distance, $h_{\text {lands }}$, the membrane thickness, $t$, width, $b$, and Young's modulus, $E$. The activation point (Eqs. 10 and 11) is marked with a circle; the curve before activation is plotted using the analytical model (Eq. 1a), while the dashed line after activation is plotted assuming ideal flow regulation (Eq. 13).

\section{Sensitivity of activation pressure and flow rate to input parameters}

A sensitivity analysis was run with the parametric model to illustrate the effect of input values on the activation pressure and flow rate. The parameters varied in the analysis were the resistances ( $K_{\text {path }}$ and $K_{\text {chamber }}$ ), the distance between the membrane and the lands $\left(h_{\text {lands }}\right)$, the membrane thickness $(t)$, width $(b)$, and Young's modulus $(E)$ (Fig. 4). One parameter was varied at a time, with the rest kept constant at nominal values, based on typical values for inline emitters. Each parameter was sampled at four points at $75 \%, 100 \%$, $125 \%$, and $150 \%$ of its nominal value. Other inputs were kept constant, with outlet radius $r_{\text {out }}=0.6 \mathrm{~mm}$, membrane length
One input parameter was varied at a time to values of $75 \%, 100 \%$, $125 \%$, and $150 \%$ of its nominal value, with the lightest line corresponding to the minimum and the darkest corresponding to the maximum parameter value. Activation pressure and flow rate are most sensitive to the membrane thickness, due to its cubic scaling in the flexural modulus, $D$

$a=11.8 \mathrm{~mm}$, and Poisson's ratio $v=0.49$, typical of silicone rubber used for PC emitter membranes.

The sensitivity plots (Fig. 4) compliment Eqs. 10 and 11 and demonstrate the dependence of activation pressure and flow rate on each parameter. The activation pressure is seen to be most sensitive to the membrane thickness $t$. This is due to the fact that $P_{\text {act }}$ scales linearly with flexural modulus $D$, which in turn scales with $t^{3}$; therefore, $P_{\text {act }} \propto t^{3}$. The sensitivity of $P_{\text {act }}$ to the distance $h_{\text {lands }}$ is approximately linear, $P_{\text {act }} \propto h_{\text {lands }}$. The same scaling is seen between $P_{\text {act }}$ and Young's modulus $E$, stemming from the linearity of flexural modulus $D$ with $E: P_{\text {act }} \propto E$. For these inputs, $Q_{\text {act }}$ scales similarly to $P_{\text {act }}$ but with reduced sensitivity, due to the power of 1/2 in Eq. 11: $Q_{\mathrm{act}} \propto t^{\frac{3}{2}}, Q_{\mathrm{act}} \propto h_{\text {lands }}^{\frac{1}{2}}$, and 
$Q_{\text {act }} \propto E^{\frac{1}{2}}$. Hydraulic behavior is also sensitive to membrane side length $b$, which enters Eq. 10 in the denominator as part of the constants $\alpha_{1}$ and $\alpha_{2}$. As side length increases, the membrane deflects more, resulting in earlier contact with the lands at lower $P_{\text {act }}$ and $Q_{\text {act }}$.

The sensitivity of $P_{\text {act }}$ to $K_{\text {path }}$ and $K_{\text {chamber }}$ is low, as a change in one affects both the numerator and denominator in Eq. 10. Conversely, $Q_{\text {act }}$ is much more sensitive to $K_{\text {path }}$ than to $K_{\text {chamber }}$, as the term multiplied by $K_{\text {chamber }}$ in the denominator of Eq. 11 is nearly negligible compared to the term multiplied by $K_{\text {path }}$, due to the very low ratio of areas of the outlet and the membrane.

While this analysis is for local sensitivity around a sample geometry, these trends are generalizable, as long as the assumptions used in the model derivations remain valid as the geometry is varied. It can be concluded that geometric and material features-especially the membrane's thickness and side lengths-play a large role in the emitter's hydraulic behavior. For example, a $25 \%$ increase in membrane thickness, with all else held constant, results in an $95 \%$ increase in $P_{\text {act }}$ and a $40 \%$ increase in $Q_{\text {act }}$. Depending on the design and manufacturing constraints, any of these parameters can be manipulated by a designer to achieve desired activation pressure and flow rate.

\section{Experimental methods}

\section{Prototyping method for inline drip emitters and its validation}

A prototyping method for inline PC emitters was developed to facilitate model validation and testing of new designs, as the commercial emitter manufacturing process is too inflexible to be used effectively in the design stage. Inline PC emitters are manufactured by injection molding the plastic body and cover of the emitter. After molding, the two parts are ultrasonically welded with a membrane between them, sealing the emitter. Finally, the assembled emitter is heat-welded inside the lateral tube as the tube is extruded. As this process requires significant time and equipment, a simplified prototyping method using CNC milling was developed and verified to ensure its ability to replicate the geometry and hydraulic performance of a commercial injection-molded dripper.

The prototyping setup consisted of three rectangular aluminum plates held together by screws at four corners (Fig. 5a). The geometry of the emitter cover was CNC machined into the top plate, with the inlet threaded for attaching a tubing fixture. The geometry of the emitter body was machined into the middle plate, with the

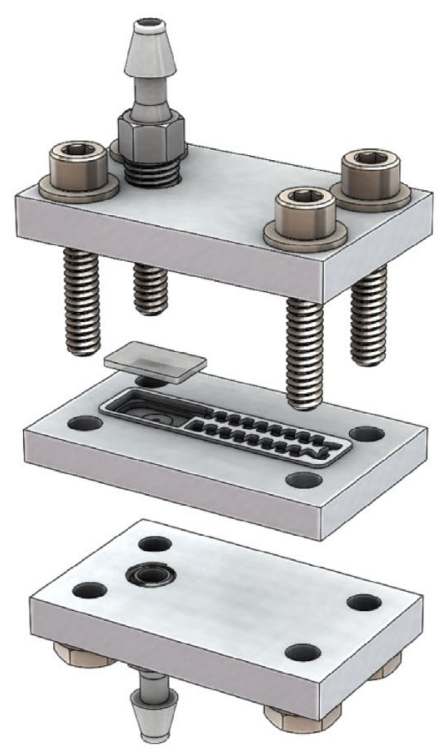

(a)

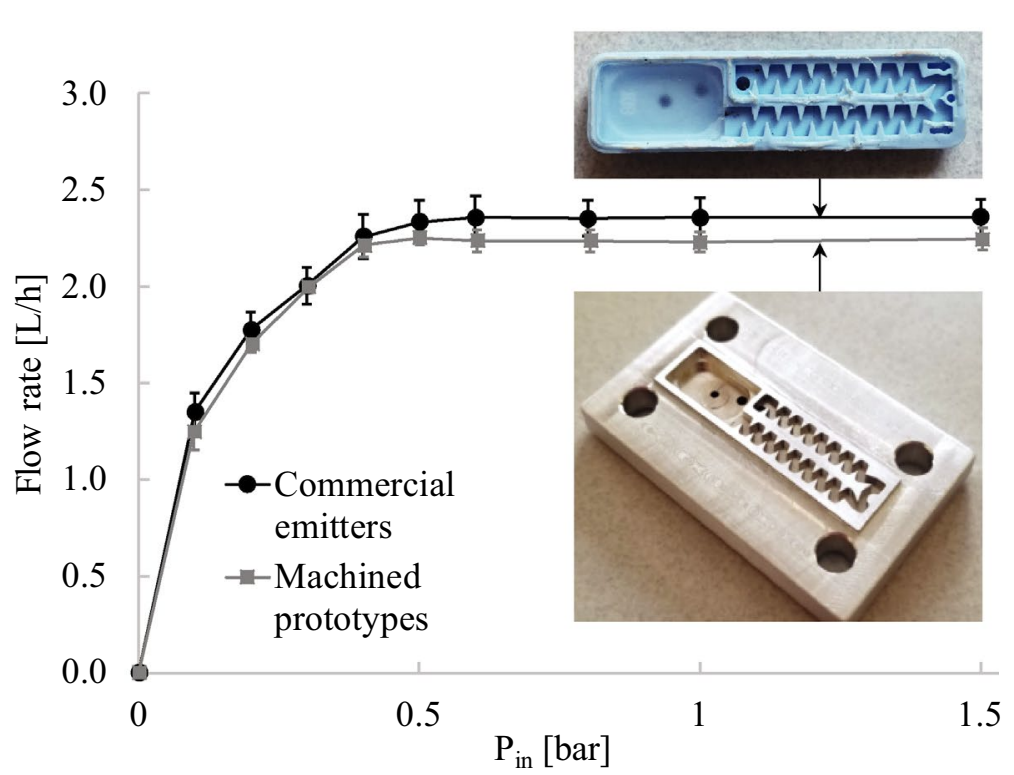

(b)
Fig. 5 Inline emitter prototyping method used for model validation and design testing. a Exploded view of the prototype assembly. Three aluminum plates are held together by screws at the corners, with internal emitter features machined in the top and middle plates. The membrane is placed on its seat in the middle plate. b Flow rate versus inlet pressure for the prototype replicating the $2 \mathrm{~L} / \mathrm{h}$ TurboCascade
PC emitter (Jain Irrigation, Ltd.), plotted as the average and standard deviation measured from two prototype duplicates. The prototypes demonstrate a close fit to the measured flow rates of commercial injection-molded emitters, plotted as the average and standard deviation measured from 12 emitters. Photographs of the commercial and prototype emitter bodies appear in the inset 
tortuous path and membrane chamber on the top face, and the passage conveying water from the tortuous path to the membrane chamber on the bottom face. The bottom plate was used as the cover for this passage (in commercial emitters, this passage is covered by the lateral tube welded to the emitter bottom face). Aluminum 6061 was used as the prototype material to maintain tight tolerances during the milling process.

To avoid leaks, the body geometry was embossed, creating a narrow ridge around the perimeter that concentrated the clamping force from the screws onto a small area and formed a seal around the flow path. For all prototype tests, screws were tightened to a consistent torque of $3.4 \mathrm{Nm}$, experimentally determined to prevent leaking at all pressures while minimizing any sensitivity to the clamping force. Gaskets were not used for sealing between aluminum plates, as their low stiffness created difficulty in maintaining consistent flow path dimensions, especially in the tortuous path. The flow rate through an emitter is highly sensitive to changes in the tortuous path cross-section, which affect $K_{\text {path }}$, as evidenced by the sensitivity analysis (Fig. 4).

This method was validated by replicating flow-pressure behavior of a commercial inline PC emitter in a prototype matching the commercial emitter's geometric features. A 2 L/h emitter manufactured by Jain Irrigation, Ltd. (Jain Irrigation Systems Ltd 2019) was chosen for the comparison. Two duplicate prototypes were machined with geometric features

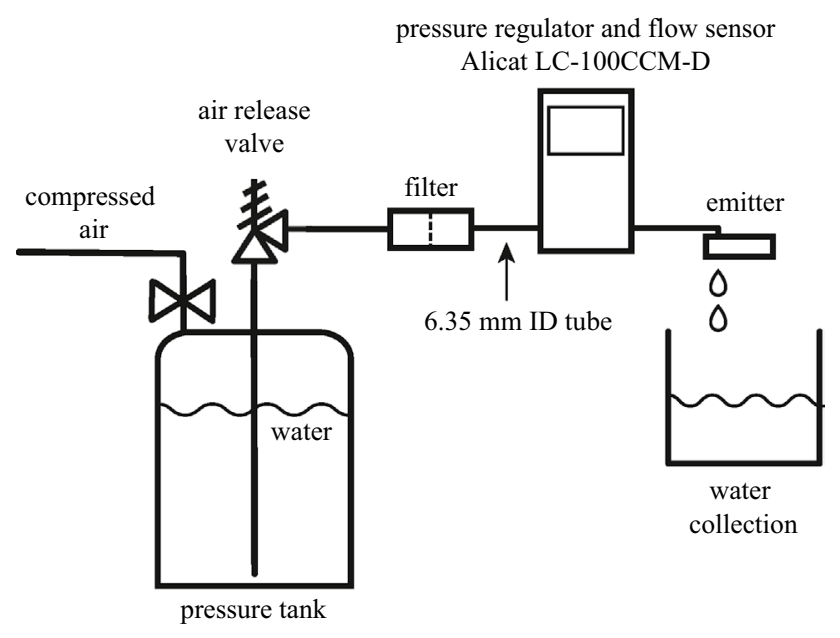

Fig. 6 Diagram of the hydraulic setup used to measure pressures and flow rates from commercial and prototype emitters. A tank containing compressed air and water was connected via flexible clear tubing to an air release valve, a $20-\mu \mathrm{m}$ inline filter, and a programmable pressure regulator and flow sensor (Alicat LC-100CCM-D). This device was connected to a computer and programmed to measure the flow rate while stepping the downstream water pressure between 5 and 150 $\mathrm{kPa}$. A commercial emitter or an emitter prototype was connected to the flow regulator via $15 \mathrm{~cm}$ of $6.35 \mathrm{~mm}$ ID tubing with a plastic tube fitting at each end identical to those of the injection-molded commercial dripper (within $\pm 0.03 \mathrm{~mm}$ ), and the hydraulic performance of each prototype was tested twice (per "Hydraulic testing procedure") using membranes from the commercial drippers. Duplicate test results were averaged. This comparison demonstrated good agreement between the flow-pressure curve of the prototype and commercial emitters (Fig. 5b), with a maximum error of $8 \%$ at a pressure of $10 \mathrm{kPa}(0.1 \mathrm{bar})$, and an average error of $5 \%$ in the regulated flow rate (estimated as the mean of all flow rates above $50 \mathrm{kPa}(0.5 \mathrm{bar})$ ). The close match between prototypes and injection-molded drippers suggests that prototypes of new designs would perform similarly when converted to injection molded commercial products, mitigating risk in the design process.

\section{Hydraulic testing procedure}

To test the pressure-flow behavior of commercial and prototype emitters, a tank containing compressed air and water was connected via flexible tubing $(9.53 \mathrm{~mm}$ OD, $6.35 \mathrm{~mm}$ ID) to an air release valve, a $20-\mu \mathrm{m}$ filter, a programmable pressure regulator and flow sensor (Alicat LC-100CCM-D, $\pm 3 \mathrm{kPa}$ for pressure, $\pm 0.12 \mathrm{~L} / \mathrm{h}$ for flow rate), and either an emitter prototype assembly (Fig. 5a) or a piece of tubing with a bonded commercial emitter (Fig. 6). The water pressure measured by the regulator was assumed equal to the pressure at the inlet of the emitter, as the pressure drop through the tube and fittings between the regulator and the emitter was estimated to be under $10 \mathrm{~Pa}$ at all measured flow rates, well below the uncertainty of the pressure sensor. The pressure regulator was connected to a computer and programmed to cycle through a range of pressure setpoints, starting at $5 \mathrm{kPa}(0.05 \mathrm{bar})$, stepping from 10 to 100 $\mathrm{kPa}(0.1-1.0 \mathrm{bar})$ at intervals of $10 \mathrm{kPa}(0.1 \mathrm{bar})$, and ending at $150 \mathrm{kPa}(1.5 \mathrm{bar})$. The pressure was stepped both up and down during each test to note any hysteresis. Before each test, the emitter was primed by cycling twice between maximum and minimum pressures. Pressure was maintained for 60 seconds at each setpoint, with pressure and flow rate recorded to a file every second. These time series were subsequently processed into flow rate versus pressure curves as follows: for each pressure setpoint, readings before pressure had equilibrated to $\pm 1 \%$ of the setpoint were filtered out, and the mean of the remaining values was taken as the flow rate for the dripper at that pressure.

\section{Use of commercial and prototype emitters for model validation}

The proposed model was validated by comparing the activation pressure and flow rate it predicted to measurements from six emitter models: three commercial emitters and 
Table 1 Geometric and material properties of commercial and prototype emitters used for model validation

\begin{tabular}{|c|c|c|c|c|c|c|c|}
\hline \multirow[t]{2}{*}{ Param } & \multirow[t]{2}{*}{ Unit } & \multicolumn{3}{|c|}{ Commercial emitters } & \multicolumn{3}{|c|}{ Prototype emitters } \\
\hline & & $1.1 \mathrm{~L} / \mathrm{h}$ & $1.6 \mathrm{~L} / \mathrm{h}$ & $2.0 \mathrm{~L} / \mathrm{h}$ & 1 & 2 & 3 \\
\hline$K_{\text {path }}$ & $\mathrm{Pa} \mathrm{h}^{2} / \mathrm{L}^{2}$ & $25,580 \pm 1398$ & $12,913 \pm 1880$ & $8445 \pm 532$ & $1075 \pm 112$ & $1075 \pm 112$ & $4138 \pm 97$ \\
\hline$K_{\text {chamber }}$ & $\mathrm{Pa} \mathrm{h}^{2} / \mathrm{L}^{2}$ & $476 \pm 26$ & $1446 \pm 211$ & $87 \pm 6$ & $374 \pm 65$ & $331 \pm 42$ & $584 \pm 142$ \\
\hline$h_{\text {lands }}$ & $\mathrm{mm}$ & $1.01 \pm 0.02$ & $1.07 \pm 0.01$ & $1.15 \pm 0.01$ & $1.12 \pm 0.01$ & $0.65 \pm 0.01$ & $0.66 \pm 0.01$ \\
\hline$r_{\text {out }}$ & $\mathrm{mm}$ & $0.47 \pm 0.02$ & $0.56 \pm 0.01$ & $0.63 \pm 0.01$ & $0.60 \pm 0.01$ & $0.60 \pm 0.01$ & $0.60 \pm 0.01$ \\
\hline$t$ & $\mathrm{~mm}$ & $1.40 \pm 0.01$ & $1.40 \pm 0.01$ & $1.40 \pm 0.01$ & $1.20 \pm 0.01$ & $1.20 \pm 0.01$ & $1.20 \pm 0.01$ \\
\hline$a$ & $\mathrm{~mm}$ & $11.76 \pm 0.02$ & $11.79 \pm 0.05$ & $11.79 \pm 0.04$ & $11.60 \pm 0.01$ & $11.60 \pm 0.01$ & $11.60 \pm 0.01$ \\
\hline$b$ & $\mathrm{~mm}$ & $6.88 \pm 0.03$ & $6.90 \pm 0.03$ & $6.90 \pm 0.01$ & $6.80 \pm 0.01$ & $6.80 \pm 0.01$ & $6.80 \pm 0.01$ \\
\hline$E$ & $\mathrm{MPa}$ & $2.13 \pm 0.15$ & & & & & \\
\hline$v$ & - & $0.49 \pm 0.01$ & & & & & \\
\hline$\overline{w_{\text {chan }}}$ & $\mathrm{mm}$ & $0.43 \pm 0.01$ & $0.49 \pm 0.02$ & $0.49 \pm 0.01$ & $0.70 \pm 0.01$ & $0.70 \pm 0.01$ & $0.70 \pm 0.01$ \\
\hline$h_{\text {chan }}$ & $\mathrm{mm}$ & $0.04 \pm 0.01$ & $0.07 \pm 0.01$ & $0.09 \pm 0.01$ & $0.10 \pm 0.01$ & $0.08 \pm 0.01$ & $0.08 \pm 0.01$ \\
\hline$L_{\text {chan }}$ & $\mathrm{mm}$ & $2.00 \pm 0.01$ & $1.92 \pm 0.02$ & $1.84 \pm 0.01$ & $1.78 \pm 0.01$ & $1.78 \pm 0.01$ & $1.78 \pm 0.01$ \\
\hline
\end{tabular}

three custom prototypes (Table 1). The commercial emitters were TurboCascade PC 1.1 L/h, 1.6 L/h, and $2.0 \mathrm{~L} / \mathrm{h}$ models from Jain Irrigation, Ltd. Three custom prototypes were fabricated to capture further geometrical variations not seen in these commercial emitters. The prototypes varied from the commercial emitters in their tortuous path geometry, the height of the membrane above the lands, and the dimensions of the channel and lands. The tortuous paths from the six commercial and prototype emitters are described in the Appendix, "Experimental measurements of tortuous path resistance". Prototype emitters 1 and 2 used the same tortuous path geometry (labeled Path A in "Experimental measurements of tortuous path resistance"), and prototype emitter 3 used tortuous path B. The prototypes were constrained to using available commercial emitter membranes in two thicknesses (1.2 and $1.4 \mathrm{~mm})$, with other membrane parameters kept constant.

The commercial emitters were disassembled and their dimensions were measured using a dial indicator (Mitutoyo $2416 \mathrm{~S}, \pm 0.01 \mathrm{~mm}$ ) for vertical dimensions and a digital microscope (AmScope H800-DAB-96S-HD1080) for horizontal dimensions. Three samples of each commercial emitter were measured and averaged. The dimensions of the prototypes were measured using the same procedure, with one sample of each. Membrane thickness was measured with a test indicator mounted on a height gauge (Machine DRO ME-HG-PRO-500, $\pm 0.05 \mathrm{~mm}$ ), ensuring minimal load from the measuring tip so as not to compress the silicone membrane during measurement, for three samples of each thickness. All dimensions were recorded as averages with uncertainty estimated as the maximum of the measured standard deviation or the accuracy of the measuring tool (Table 1). The dimensions of the features below the membrane-the channel height, width, and length-were recorded for replicability (Table 1) but not used directly in the analytical model, as these dimensions govern emitter behavior after activation, while the present model accounts for behavior up to activation.

The resistances of the tortuous path $\left(K_{\text {path }}\right)$ and membrane chamber ( $\left.K_{\text {chamber }}\right)$ were measured experimentally. For the two tortuous path geometries used in custom prototypes (Fig. 3a), the tortuous paths were machined in isolation and tested analogously to full emitter prototypes. For commercial emitters bonded inside lateral tubes, the tortuous path resistance was measured by manually adding an extra outlet in the tube directly after the end of the tortuous path, where water could exit before entering the membrane chamber; this isolated the measured resistance from any effects of membrane deformation, allowing it to be attributed primarily to the tortuous path. The resistance of each tortuous path in Table 1 is equal to the mean of all $K_{\text {path }}$ values calculated from measured pressures ( $5 \mathrm{kPa}$ and above) and corresponding flow rates $\left(K_{\text {path }}=P / Q^{2}\right)$; the uncertainty is the standard deviation of measured values. Appendix, "Experimental measurements of tortuous path resistance" provides further details about their. For all commercial and prototype emitters, $K_{\text {chamber }}$ was estimated as the difference between the total measured emitter resistance at activation pressure and its measured tortuous path resistance. In the absence of physical prototypes, these resistances can be estimated with CFD simulation, with care taken to calibrate the CFD model to ensure its accuracy.

The hydraulic behavior before activation for each emitter was compared to the behavior modeled using the emitter's geometric properties and resistances as inputs. The goodness of fit was assessed by comparing the modeled $P_{\text {act }}$ and $Q_{\text {act }}$ (Eqs. 10 and 11) to measured values. For the experimental measurements, $P_{\text {act }}$ was estimated as the minimum pressure at which the measured flow rate was within $\pm 5 \%$ of $Q_{\text {act }}$, while $Q_{\text {act }}$ was calculated as the mean of all flow rates 
Table 2 Comparison of measured and modeled activation pressures and flow rates for three commercial emitters and three prototypes

\begin{tabular}{|c|c|c|c|c|c|c|c|}
\hline \multirow[t]{2}{*}{ Value } & \multirow[t]{2}{*}{ Units } & \multicolumn{3}{|c|}{ Commercial emitters } & \multicolumn{3}{|c|}{ Prototype emitters } \\
\hline & & $1.1 \mathrm{~L} / \mathrm{h}$ & $1.6 \mathrm{~L} / \mathrm{h}$ & $2.0 \mathrm{~L} / \mathrm{h}$ & 1 & 2 & 3 \\
\hline Measured $P_{\text {act }}$ & $\mathrm{kPa}$ & $30 \pm 5$ & $40 \pm 5$ & $40 \pm 5$ & $40 \pm 5$ & $20 \pm 5$ & $15 \pm 5$ \\
\hline Measured $Q_{\text {act }}$ & $\mathrm{L} / \mathrm{h}$ & $1.10 \pm 0.02$ & $1.60 \pm 0.01$ & $2.34 \pm 0.07$ & $5.20 \pm 0.26$ & $3.64 \pm 0.04$ & $1.87 \pm 0.11$ \\
\hline Modeled $P_{\text {act }}$ & $\mathrm{kPa}$ & $34 \pm 8$ & $38 \pm 10$ & $39 \pm 9$ & $34 \pm 9$ & $19 \pm 4$ & $17 \pm 5$ \\
\hline Modeled $Q_{\text {act }}$ & $\mathrm{L} / \mathrm{h}$ & $1.14 \pm 0.13$ & $1.63 \pm 0.21$ & $2.14 \pm 0.23$ & $4.87 \pm 0.54$ & $3.71 \pm 0.41$ & $1.87 \pm 0.20$ \\
\hline Abs error, $P_{\text {act }}$ & $\mathrm{kPa}$ & -4 & 2 & 1 & 6 & 1 & -2 \\
\hline Abs error, $Q_{\text {act }}$ & $\mathrm{L} / \mathrm{h}$ & -0.04 & -0.03 & 0.21 & 0.33 & -0.07 & 0.0 \\
\hline Rel error, $P_{\text {act }}$ & $\%$ & $-13.3 \%$ & $5.0 \%$ & $2.5 \%$ & $15.0 \%$ & $5.0 \%$ & $-13.3 \%$ \\
\hline Rel error, $Q_{\text {act }}$ & $\%$ & $-4.1 \%$ & $-1.9 \%$ & $8.8 \%$ & $6.3 \%$ & $-2.0 \%$ & $-0.1 \%$ \\
\hline
\end{tabular}

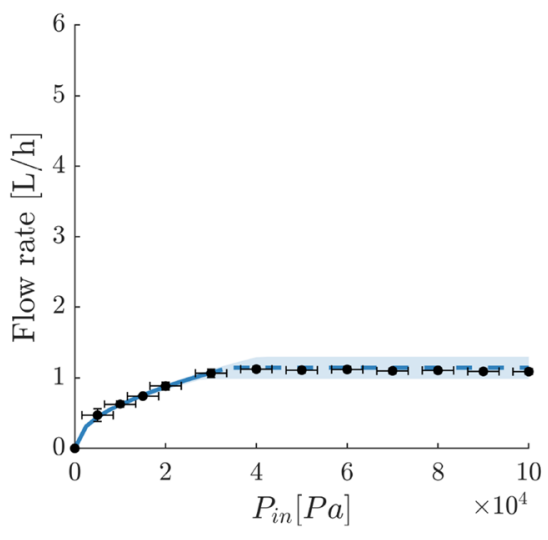

(a) Commercial $1.1 \mathrm{~L} / \mathrm{h}$

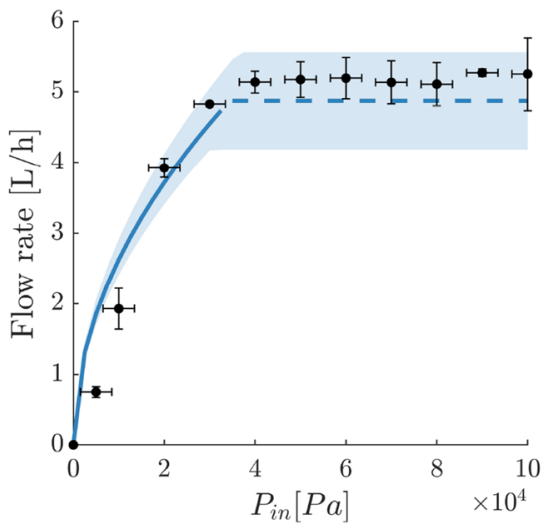

(d) Prototype 1

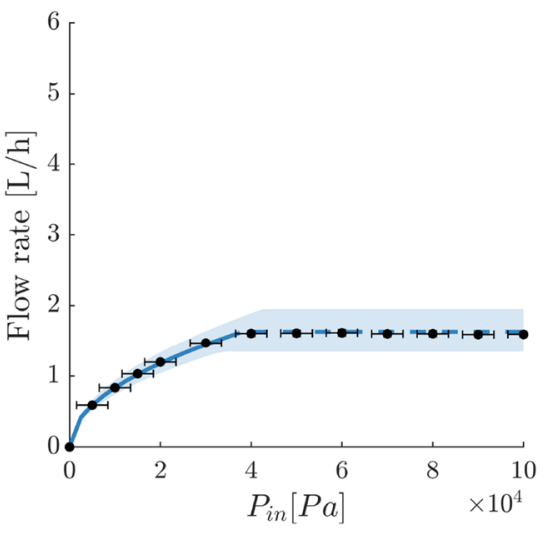

(b) Commercial $1.6 \mathrm{~L} / \mathrm{h}$

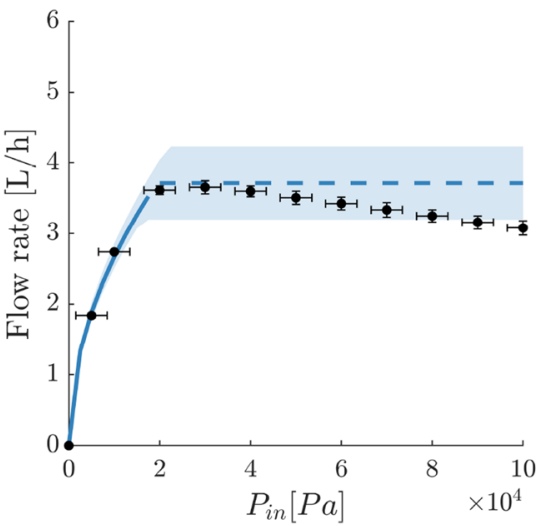

(e) Prototype 2

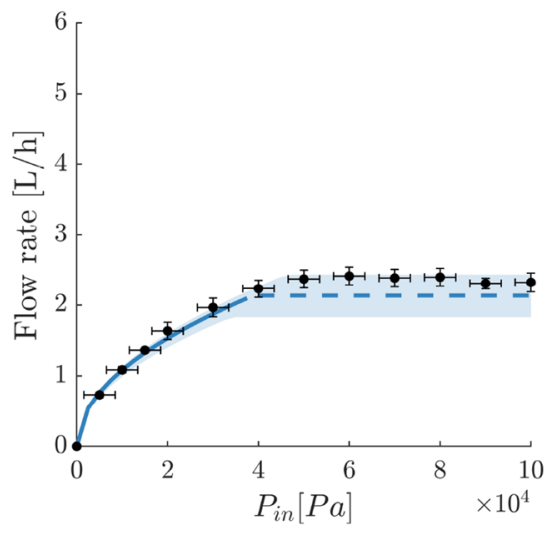

(c) Commercial $2.0 \mathrm{~L} / \mathrm{h}$

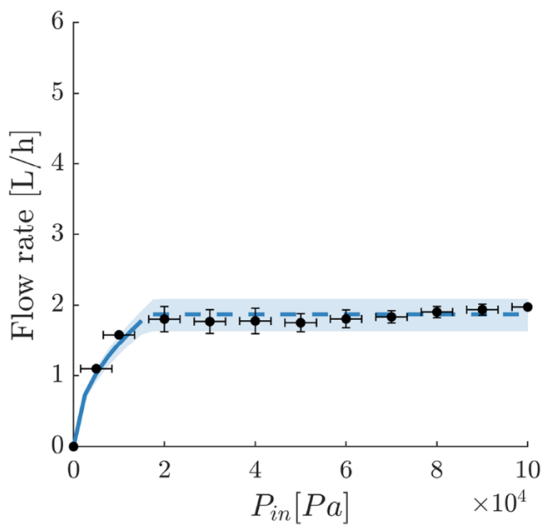

(f) Prototype 3
Fig. 7 Comparison of observed and modeled behavior for six inline emitters: three emitters commercially produced by Jain Irrigation, Ltd. (a-c), and three custom emitters prototyped in the lab (d-f). Geometric parameters for each emitter are listed in Table 1, and measured performance is quantified in Table 2. The measured hydraulic curve of each emitter is compared to the analytical model of behavior before activation. Dots represent measured values with measurement uncertainties; solid lines represent the analytically modeled behavior below activation, and dashed lines show hypothetical ideal compensating behavior after activation as defined in "Analytical scaling for operation above activation pressure" (not all prototypes achieve ideal compensation, as they were not specifically designed for it). The shaded region indicates the potential range predicted by the model considering input uncertainties 
measured at and above $P_{\text {act }}$ for that emitter. The resolution of the measured $P_{\text {act }}$ was limited by the values of the pressure setpoints used in the experiments (at intervals of every $10 \mathrm{kPa}(0.1 \mathrm{bar}))$, and hence could not be as precise as the values calculated by the model. This may affect some of the errors seen in the results, and is discussed further in "Results of model validation".

\section{Results of model validation}

The model shows good agreement to experimental performance of three commercial emitters and three prototypes (Table 2, Fig. 7). Error bars on the measured flow rate values represent the maximum of the flow sensor accuracy or the standard deviation from all measurements at a given pressure for that emitter. The pressure error bars are based on sensor accuracy, as the measured standard deviation was approximately zero in all cases. Due to the sensitivity of the model to input parameters, uncertainty ranges for the model are also shown in the plots as shaded regions (Fig 7). To calculate these ranges, four inputs were considered to have the highest uncertainty/manufacturing variation: membrane thickness $t$ and Young's modulus $E$, both of which depend on the silicone manufacturing process, and path and chamber resistances, both of which are expected to deviate slightly from their average values (e.g., as seen in Fig. 3a). The uncertainty of these inputs was estimated as follows: membrane thickness uncertainty of $\pm 0.01 \mathrm{~mm}$ is based on standard deviations of the measurements; Young's modulus uncertainty of $\pm 0.15 \mathrm{MPa}$ is based on standard deviations from experimental measurements of membrane deflection (see Appendix); $K_{\text {path }}$ and $K_{\text {chamber }}$ uncertainties are taken from the hydraulic measurements of each emitter (Table 2). Uncertainties in the remaining inputs were deemed negligible in comparison and are not included in the shaded range.

In all cases, the activation pressure was predicted within $15 \%$ of the measured value, and the activation flow rate within $8.8 \%$, using the base model inputs. The largest absolute error in activation pressure was $6 \mathrm{kPa}(0.06 \mathrm{bar})$, and the maximum absolute error in flow rate was $0.33 \mathrm{~L} / \mathrm{h}$, for the emitter with the highest flow rate. The most likely sources of error include manufacturing variation in the inputs mentioned above. When uncertainty in those inputs is considered, the modeled activation ranges encompass all measured values. Another source of error is the low resolution of experimental pressure measurements, which were taken at intervals of $10 \mathrm{kPa}(0.1 \mathrm{bar})$, leading to an estimated uncertainty of $5 \mathrm{kPa}$ in the measured $P_{\text {act }}$, corresponding to relative uncertainty of $12-33 \%$. Smaller intervals between pressure setpoints (e.g., 1-2 $\mathrm{kPa}$ ) would provide more precision in measured $P_{\text {act }}$ values and in the error estimate. Additionally, the pressure sensor's uncertainty of $3 \mathrm{kPa}$ is high relative to the measured value at the lowest pressures (5 and $10 \mathrm{kPa}$ ) (Fig. 7). This limits the accuracy of the low-pressure region of the emitter's hydraulic curve, and the values of $K_{\text {path }}$ calculated at those pressures (Fig. 9).

Assumptions used in model derivation may account for some of the discrepancies between measured and modeled behavior. For cases (c) and (d), the base model under-predicts the activation flow rate and pressure. This may be due to a departure from linearity for membrane deflection in the higher deflection range, as these two emitters have the largest distance to the lands and, as a result, the largest extent of membrane deformation. The assumption of constant $K_{\text {chamber }}$ is expected to lead to greatest errors for emitters with low $K_{\text {path }}$, such as (d)-(f), where $K_{\text {chamber }}$ approaches the same order of magnitude as $K_{\text {path }}$. Finally, the assumption of constant $K_{\text {path }}$ will be invalid in the lowest flow rate and pressure ranges, when flow in the tortuous path becomes more laminar and its dependence on $R e$ becomes more pronounced.

Overall, the model is flexible enough to predict the emitter activation point for a range of geometries, with flow rates ranging from 1 to $5 \mathrm{~L} / \mathrm{h}$ and activation pressures from 15 to $40 \mathrm{kPa}(0.15-0.4$ bar $)$.

\section{Design of a PC inline drip emitter with low activation pressure}

The model and prototyping method were applied to the design of a low-activation-pressure emitter, using the commercial design with $2 \mathrm{~L} / \mathrm{h}$ nominal flow rate and $P_{\text {act }}$ of 0.4 bar as the basis. A systematic dripper redesign process for lowering activation pressure at this flow rate under a set of constraints is presented below. The dimensions and material properties of the membranes from the commercial emitters $(a, b, t, E, v)$ (Table 1) were kept constant due to manufacturing constraints (the commercial emitter membranes are injection molded for Jain Irrigation, Ltd., in one standard size). Therefore, the parameters that were allowed to vary were $h_{\text {lands }}, K_{\text {path }}$, and $K_{\text {chamber }}$.

Sensitivity analysis (Fig. 4) indicated that reducing $h_{\text {lands }}$ and $K_{\text {path }}$ would be most effective in reducing activation pressure: a reduction in $K_{\text {path }}$ makes the initial flow rate versus pressure curve before activation steeper, and a simultaneous reduction in $h_{\text {lands }}$ forces that curve to level off at a lower activation pressure. Therefore, the redesign required lowering $K_{\text {path }}$ of the commercial $2 \mathrm{~L} / \mathrm{h}$ emitter $\left(K_{\text {path,comm2L } / \mathrm{h}}=8445 \pm 532 \mathrm{~Pa} \mathrm{~h}^{2} / \mathrm{L}^{2}\right)$ and determining the corresponding change in $h_{\text {lands }}$ needed to maintain the original flow rate. Two prototype tortuous paths, which had been characterized previously as having lower path resistances than $K_{\text {path,comm2L/h }}$, were considered for use in the redesigned emitter (Fig. 3a, Table 1): $K_{\text {path,A }}=1075 \pm 112$ 
$\mathrm{Pa} \mathrm{h}^{2} / \mathrm{L}^{2}$ ) (used in Prototype 2) and $K_{\text {path,B }}=4138 \pm 97$ $\mathrm{Pa} \mathrm{h}^{2} / \mathrm{L}^{2}$ (used in Prototype 3). The geometry of the channel $\left(w_{\text {chan }}, h_{\text {chan }}, L_{\text {chan }}\right)$, lands, and outlet radius $\left(r_{\text {out }}\right)$ from these prototypes were kept constant, with $K_{\text {chamber }}$ assumed to remain the same as in the tested prototypes (Table 1).

The values of the parameters retained from the original commercial emitter $(a, b, t, E, v)$ and the two pairs of resistance values under consideration were entered into the model (Eqs. 10 and 11) to determine the distance $h_{\text {lands }}$ that would provide the target flow rate of $2.3 \mathrm{~L} / \mathrm{h}$ (the average flow rate measured for the commercial emitter), and compute the corresponding activation pressure for the two potential redesigns. For the design with $K_{\text {path,A }}=1075 \pm 112 \mathrm{~Pa} \mathrm{~h}^{2}$ $/ \mathrm{L}^{2}$ and $K_{\text {chamber, } \mathrm{A}}=331 \pm 42 \mathrm{~Pa} \mathrm{~h}^{2} / \mathrm{L}^{2}$, the lands distance required for the target flow rate was calculated as $h_{\text {lands, } \mathrm{A}}=$ $0.17 \mathrm{~mm}$, with a predicted activation pressure $P_{\text {act, } \mathrm{A}}=8$ $\mathrm{kPa}\left(0.08\right.$ bar). For the design with $K_{\text {path,B }}=4138 \pm 97$ and $K_{\text {chamber, } \mathrm{B}}=584 \pm 142$, the required $h_{\text {lands, } \mathrm{B}}$ was $0.66 \mathrm{~mm}$, with activation pressure $P_{\text {act, B }}=23 \mathrm{kPa}(0.23 \mathrm{bar})$.

The latter design with $h_{\text {lands, } \mathrm{B}}=0.66 \mathrm{~mm}$ was selected for further prototyping and testing, as the smaller $h_{\text {lands, } \mathrm{A}}=0.17$ $\mathrm{mm}$ required for the alternative design was deemed impractical for a commercial product. In a commercial drip emitter, such a small gap between the membrane and lands could cause several complications: it could increase the sensitivity of emitter flow rate to manufacturing variation and the emitter's clogging tendency. The first consideration can be explained via Eqs. 10 and 11: a variation in $h_{\text {lands }}$ of \pm 0.02 $\mathrm{mm}$-which can be expected for injection-molded commercial emitters (Table 1) — would be $11.8 \%$ of the nominal gap size of $0.17 \mathrm{~mm}$ and lead to a variation of $\pm 6.1 \%$ in $Q_{\text {act }}$; in contrast, the same absolute variation in $h_{\text {lands }}$ would only be $3.0 \%$ of the larger $0.66 \mathrm{~mm}$ gap, corresponding to a variation of $\pm 1.5 \%$ in $Q_{\text {act }}$. The second consideration is based on the fact that suspended particles in irrigation water that pass through the filtration system could get trapped below the membrane, affecting the emitter flow rate. Common filter mesh sizes recommended for use in drip irrigation are 100-200 $\mu \mathrm{m}$ (Phocaides 2007), which is comparable in magnitude to the gap of $0.17 \mathrm{~mm}(170 \mu \mathrm{m})$, increasing the risk of particles getting trapped. In contrast, larger $h_{\text {lands }}$ would allow a trapped particle to be flushed out when the membrane returns to its undeformed position. For these reasons, the redesigned emitter used $h_{\text {lands, B }}$ and the corresponding $K_{\text {path,B. }}$

To create a tortuous path with a target resistance, emitter designers can rely on a systematic modification of a previously characterized tortuous path with a known resistance. A standard tortuous path is composed of identical repeating units along its length (Fig. 2a); a fluid in steady, hydrodynamically fully developed flow should attain the same velocity field and pressure drop across each unit (Zhang et al.

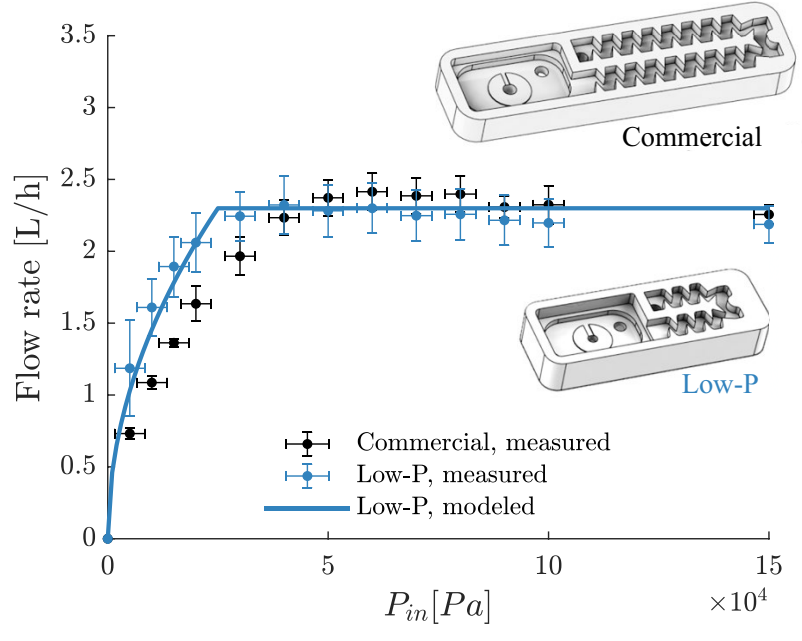

Fig. 8 Comparison of modeled and observed behavior for a prototype of the emitter redesigned for low activation pressure, plotted with the curve of the commercial emitter used as the basis for the redesign (Jain Irrigation, Ltd., TurboCascade $2 \mathrm{~L} / \mathrm{h}$ ). The measured activation pressure of the low-pressure design is $38 \% \pm 12 \%$ lower than that of the basis commercial design

2011a; Yu et al. 2018). Therefore, $K_{\text {path }}$ can be adjusted by proportionally scaling the number of repeating units. This procedure was used for the low-pressure redesign. The tortuous path of the commercial $2 \mathrm{~L} / \mathrm{h}$ emitter was verified by CFD simulation to have approximately linear pressure drop with each repeating unit, except in the developing flow regions at the start of the path and after the U-turn (see Appendix, Fig. 12, for detailed simulation results). It was adapted for the low-pressure design by reducing the number of units from 16 to 6 . With all other dimensions kept constant, this change was expected to result in a resistance of $6 / 16$ of $K_{\text {path,comm2L/h }}$, or $3167 \pm 200 \mathrm{~Pa} \mathrm{~h}^{2} / \mathrm{L}^{2}$. After the path was fabricated by CNC machining, its resistance was measured to be $K_{\text {path,B }}=4138 \pm 97 \mathrm{~Pa} \mathrm{~h}^{2} / \mathrm{L}^{2}$. The difference between the expected and measured resistances can be traced to the assumption of neglecting the pressure drop in the developing flow regions, and to machining tolerances, which resulted in some dimensional deviations from the design, particularly in the gap between teeth (the machined gap was $0.05 \mathrm{~mm}$ smaller than the commercial path's gap of $0.10 \mathrm{~mm}$, which increased the flow resistance) (Appendix, Table 3). The principle of linearity of path resistance with number of units can be used for initial design of tortuous paths with a target resistance; nevertheless, experimental validation of $K_{\text {path,B }}$ after fabrication of a prototype is recommended, due to its sensitivity to manufacturing variation.

The protocols from "Experimental methods" were followed to fabricate and test the full redesigned emitter with $K_{\text {path,B }}$ and $h_{\text {lands,B }}$, comparing its hydraulic performance to the modeled results and to the original commercial emitter 
(Fig. 8). The measured average flow rate of $2.25 \pm 0.17 \mathrm{~L} / \mathrm{h}$ matched well to the modeled flow rate of $2.3 \mathrm{~L} / \mathrm{h}$, with a relative error of $2 \%$. The activation pressure measured for the prototype was $25 \pm 5 \mathrm{kPa}(0.25 \pm 0.05 \mathrm{bar})$, with an error of $9 \%$ from the modeled $P_{\mathrm{act}, \mathrm{B}}=23 \mathrm{kPa}$. These errors were within expectations based on model validation results. The measured activation pressure of the redesigned emitter was $38 \pm 12 \%$ below that of the original commercial emitter with an activation pressure of $40 \mathrm{kPa}(0.4 \mathrm{bar})$ (Fig. 8).

\section{Discussion}

Despite the simplicity of the analytical model for inline PC drip emitters presented in this work, it was shown to robustly predict how geometric changes in the membrane, compensating chamber, and flow resistances affect the resulting activation pressure and flow rate. The present model is based on a common commercial architecture (Fig. 2a) but may be adapted to other geometries, including those with different membranes shapes, membrane boundary conditions, and flat or cylindrical bodies. This model can be useful as a parametric design tool for irrigation engineers, systematizing and accelerating the emitter design process instead of relying on a trial-and-error approach. The model's parametric nature offers insights on trade-offs that can guide designers in choosing parameter values under certain design constraintsinsights that are not easily codified with the empirical design processes used by irrigation companies. The modeled sensitivities can also inform the setup of the manufacturing production line by identifying which processes need to produce the tightest tolerances to obtain low performance variation.

The utility of the parametric model was demonstrated by redesigning a commercial emitter for lower activation pressure under a set of imposed constraints. The resulting prototype reduced $P_{\text {act }}$ by $38 \%$ compared to the commercial emitter it was based on, while maintaining a similar flow rate. Such low-pressure PC emitters can be an effective tool to lower the costs of drip irrigation systems by requiring less pumping power. This can reduce the energy cost for on-grid systems, and result in substantial savings for off-grid (e.g., solar-powered) drip systems by reducing the capital cost of the solar array. Changing activation pressure from $40 \mathrm{kPa}(0.4 \mathrm{bar})$ to $25 \mathrm{kPa}(0.25 \mathrm{bar})$ is estimated to reduce off-grid system cost by $10 \%$ (based on the calculation in Shamshery and Winter (2018) for surface water-pumped systems India, adjusted for the current activation pressures). This could increase adoption of drip systems by smallholder farmers in areas where power supplies are limited or unavailable, potentially enabling improved crop production.

The presented design study is not comprehensive, and was used only to show the utility of the theory and the process of how an emitter could be designed within given constraints. Given greater design freedom with more than one adjustable parameter, the model could be used in an optimization algorithm with a desired objective function. For instance, an objective function for a minimum activation pressure at a target flow rate could be defined as the root mean square error (RMSE) between the modeled flow rate and the target flow rate, defined as a constant for a vector of inlet pressures between zero and a maximum operating pressure, i.e., having an activation pressure of $0 \mathrm{kPa}$. Using a constrained nonlinear optimization solver with reasonable parameter bounds will output the optimal vector of geometric, material, and resistance inputs that minimize the objective function.

The limitations of the model must be considered when applying the theory presented in this work to dripper design. It is important to ensure that the model's assumptions are satisfied within the geometric ranges under consideration. If they are not satisfied, the model can be adjusted, as needed, to incorporate different sub-models (i.e., for membrane deflection, tortuous path resistance, etc.) with additional dependencies. For example, a varying path resistance with Reynolds number or non-linearity in membrane bending could be incorporated into Eqs. 1a and 9, although these changes will necessitate an iterative solution for $P_{\text {act }}$ and $Q_{\text {act }}$. Another assumption used in the model is that the resistance of the particle filter grid at the emitter inlet is negligible in comparison to other resistances in the emitter. For the three commercial emitters in this study, the filter resistance was estimated as a thick orifice using correlations from Cioncolini et al. (2015), found to be less than $1 \%$ of the tortuous path resistance in all cases and, therefore, neglected in the model formulation. For emitter architectures where the filter grid is extremely fine and has a non-negligible contribution to the overall pressure drop, its resistance could be added in series with the resistances in Fig. $2 \mathrm{~b}$ after $P_{\text {in }}$.

Another limitation of the present approach is the lack of an analytical model for hydraulic behavior after activation. This behavior can be simulated using numerical methods, as presented by Narain and Winter (2019), after conceptual design with the model described here.

The prototyping process includes several limitations as well, with the primary one being the sensitivity of the prototype hydraulics to defects in machining. Minor defects (e.g., burrs or scratches) may result in unintended leakage between parts of the flow path that are not designed to be interconnected. To minimize these effects, care should be taken to produce prototypes with good surface finish and minimal tool marks. Furthermore, while the prototyping method was shown to reflect the behavior of an injection-molded dripper, it has yet to be tested in the reverse direction, by injectionmolding of the prototype's geometry and bonding it into tubing to ensure that it works as anticipated. 


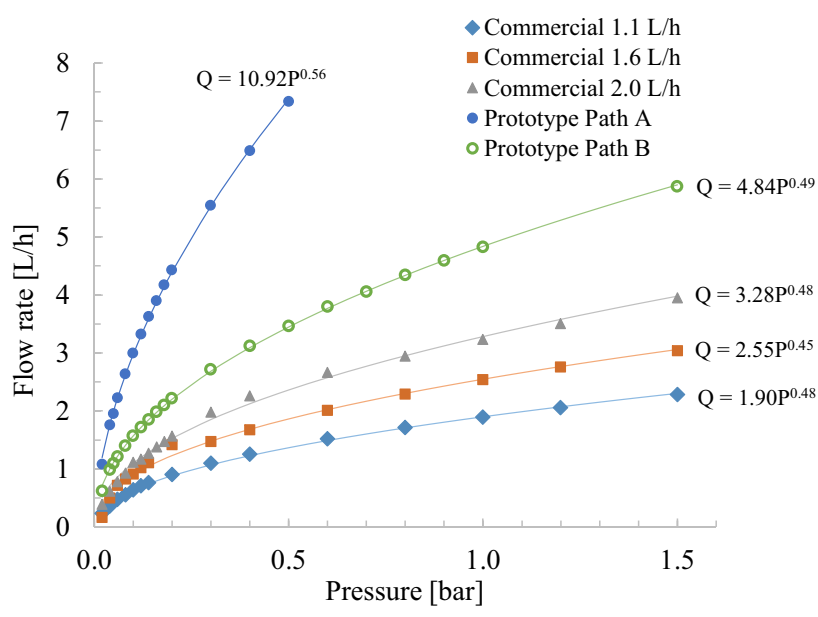

(a)

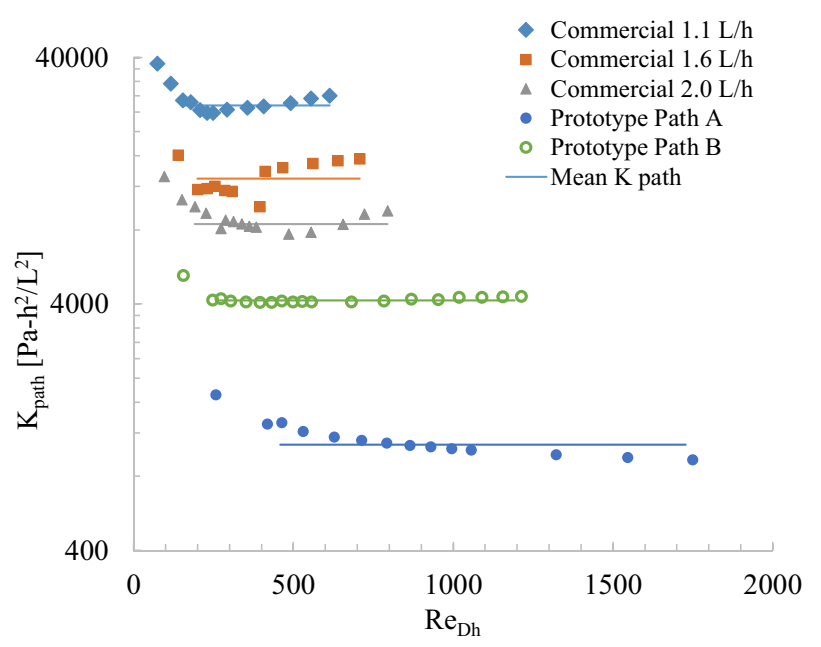

(b)

Fig. 9 Measured hydraulic properties for five sample tortuous paths of different geometries: a flow rate versus pressure; b hydraulic resistance $K_{\text {path }}$. Each path's flow rate versus pressure data points

Finally, this study did not consider the issue of emitter clogging, which is frequently seen in drip irrigation (Feng et al. 2019; Pei et al. 2014). This analysis describes the hydraulic performance of inline emitters and offers designers the ability to tune this performance by changing the emitter geometry to target a specific flow rate and activation pressure. Yet, changes in emitter geometry can affect its propensity for clogging by influencing the flow characteristics, such as locations of vortices (Feng et al. 2018; Zhang et al. 2010). Future research should explore the relationship between PC emitter geometry and membrane properties and the resulting clogging behavior under different water qualities. were fitted to the emitter power law expression, $Q=k P^{x}$ (Karmeli 1977); the resulting curve fit lines and equations are displayed on the plot

\section{Conclusions}

A method for designing and prototyping inline PC emitters with desired activation pressure and flow rates using an analytical parametric model is proposed. The analytical model presented here expands on existing literature, which has focused on numerical methods, and can aid emitter designers in systematically targeting desired performance. The suggested prototyping method can be used in conjunction with the model to validate and refine emitter designs. The match among the hydraulic performance of the prototypes, commercial emitters, and modeled results provides confidence that the theory presented here can be used for the design of commercial products.

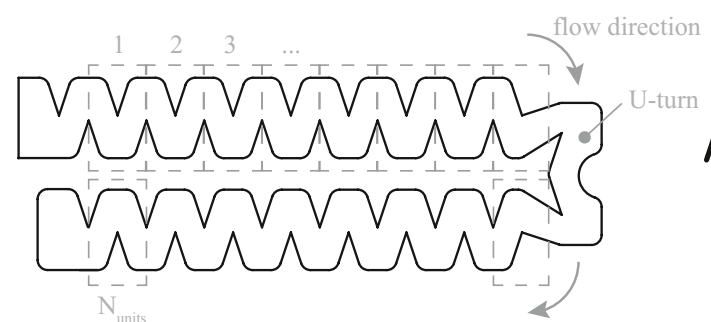

(a)

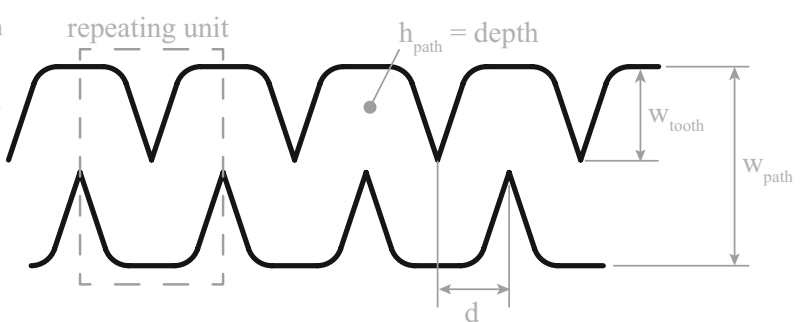

(b)
Fig. 10 Diagram of dimensions used to characterize tortuous paths. a A tortuous path consists of a number of identical repeating units, $N_{\text {units }}$, each shown with a dashed line. textbfb Dimensions that define the geometry of a tortuous path, including its depth, $h_{\text {path }}$, distance between neighboring teeth, $d$, the width of each tooth, $w_{\text {tooth }}$, and the path width, $w_{\text {path }}$. The difference $w_{\text {path }}-2 w_{\text {tooth }}$ is the gap between teeth 
Table 3 Dimensions of tortuous paths used in experiments (measured with accuracy of $\pm 0.01 \mathrm{~mm}$ ), the number of repeating units, $N_{\text {units }}$, and the mean resistance, $K_{\text {path }}$, specified with the standard deviation of all measurements

\begin{tabular}{lllllllll}
\hline Path & $d(\mathrm{~mm})$ & $h_{\text {path }}(\mathrm{mm})$ & $w_{\text {tooth }}(\mathrm{mm})$ & $w_{\text {path }}(\mathrm{mm})$ & $D_{\mathrm{h}}(\mathrm{mm})$ & $A\left(\mathrm{~mm}^{2}\right)$ & $N_{\text {units }}$ & $\mathrm{Mean} K_{\text {path }}\left(\mathrm{Pa} \mathrm{h}^{2} / \mathrm{L}^{2}\right)$ \\
\hline Comm 1.1 L/h & 0.98 & 0.74 & 1.24 & 2.57 & 0.84 & 0.72 & 20 & $25,580 \pm 1398$ \\
Comm 1.6 L/h & 1.07 & 0.92 & 1.53 & 3.14 & 0.99 & 0.99 & 18 & $12,913 \pm 1880$ \\
Comm 2.0 L/h & 1.19 & 1.07 & 1.52 & 3.14 & 1.13 & 1.28 & 16 & $8642 \pm 687$ \\
Prototype Path A & 1.26 & 1.07 & 1.35 & 3.25 & 1.16 & 1.35 & 6 & $1075 \pm 112$ \\
Prototype Path B & 1.16 & 1.05 & 1.60 & 3.25 & 1.10 & 1.22 & 6 & $4138 \pm 97$ \\
\hline
\end{tabular}

The model predicted activation pressure within $15 \%$ and flow rate within $9 \%$ of measured values for six variants of inline PC emitters. The theory and prototyping method were successfully used to redesign a commercial emitter with 2.2 $\mathrm{L} / \mathrm{h}$ flow rate to operate at $38 \%$ lower activation pressure than the original design. Compared to commercial inline PC emitters in that flow rate range, this lower-pressure design could lower the drip system pumping power and help reduce lifetime system costs. To achieve even further reductions in activation pressure, the present model could be incorporated into an optimization routine to optimize multiple input parameters at a time, within feasible parameter bounds specified by a designer.

Future work in this area may include analytical modeling of emitter behavior after activation, as well as additional testing of the robustness of the present analytical model. Physical insights from this model may also be used to inspire new dripper architectures for improved performance or lower cost.

\section{Appendix}

\section{Experimental measurements of tortuous path resistance}

Method: Tortuous path resistances for three commercial emitters and two custom prototypes were measured as described in "Experimental methods". Flow rates were measured at pressures ranging from 5 to $100 \mathrm{kPa}(0.05-1.0$ bar), except for the Prototype Path A, which was limited to maximum pressures of $50 \mathrm{kPa}(0.5 \mathrm{bar})$ by the flow sensor measurement range. The tortuous path resistance $K_{\text {path }}=\Delta P / Q^{2}$ and Reynolds number $R e_{D_{h}}=Q D_{\mathrm{h}} / A v_{\mathrm{fl}}$ were calculated for each measurement, with $Q=$ flow rate $\left(\mathrm{m}^{3} / \mathrm{s}\right), v_{\mathrm{fl}}=$ kinematic viscosity of water $\left(10^{-6} \mathrm{~m}^{2} / \mathrm{s}\right), D_{\mathrm{h}}$ and $A=$ characteristic hydraulic diameter and area of the flow path, respectively. The characteristic dimensions used for $D_{\mathrm{h}}$ and $A$ were the height of the tortuous path $h_{\text {path }}$ and the distance between two teeth $d$ (Fig. 10; Table 3). Additional dimensions for each tested tortuous path design are listed in Table 3, measured analogously to other emitter
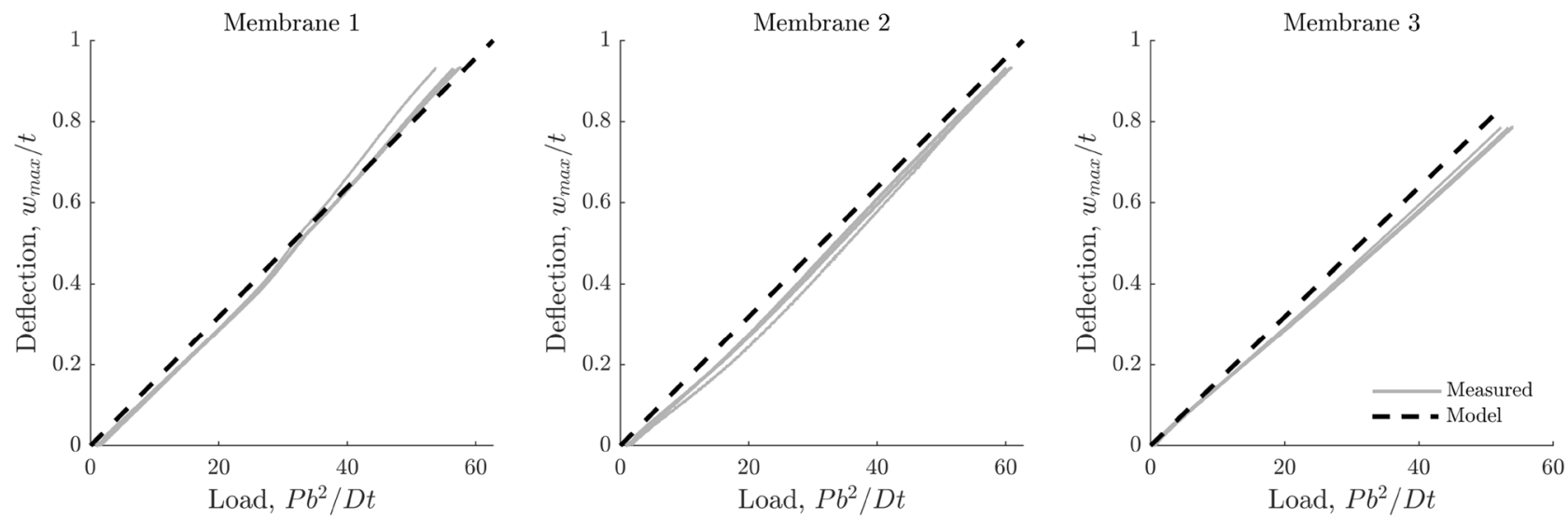

Fig. 11 Experimental measurements for the bending of three membranes with an applied concentrated load. The deflection at the center of the membrane is normalized by its thickness $t ; P$ is a concentrated load applied at the center; it is normalized by the membrane thickness, width $b$, and flexural modulus $D$. Measurements for three mem- branes at three loading speeds are plotted alongside the Kirchhoff plate bending model, with Young's modulus $E$ fitted to each experiment by least squares, then averaged among all experiments. The mean fitted $E$ value and standard deviation for the nine experiments was $E=2.13 \pm 0.15 \mathrm{MPa}$ 
dimensions with accuracy of $\pm 0.01 \mathrm{~mm}$. The number of identical units in each path (Table 3 ) is determined as shown in Fig. 10, with the start, end, and U-turn sections of the path not included in the count, as the geometry of these segments, and the corresponding pressure drop through them, differs from that of the identical units.

Results: The flow rates versus pressure data for each tortuous path are plotted in Fig. 9(a). The measured data points were curve fit in MATLAB (MathWorks Inc. 2017) to the standard emitter power law equation, $q=k P^{x}$ (Karmeli 1977). The discharge exponent ranges between 0.45 and 0.56 for all of the paths, remaining within \pm 0.06 of the fully turbulent flow exponent of
0.50 (Karmeli 1977). The highest exponent, 0.56, belongs to Prototype Path A, indicating slightly more laminar behavior than the other tortuous paths with exponents 0.45-0.49. This is likely due to Prototype Path A having a larger gap between teeth $(0.55 \mathrm{~mm})$ than the other paths (with gaps of $0.05-0.10 \mathrm{~mm}$ only) (Table 3 ), leading to less obstruction and lower turbulence in the flow through the path.

Fig. 9b plots the path resistances versus Reynolds number, with the mean $K_{\text {path }}$ shown as a horizontal line. The mean and standard deviation for each $K_{\text {path }}$ are reported in Table 3.
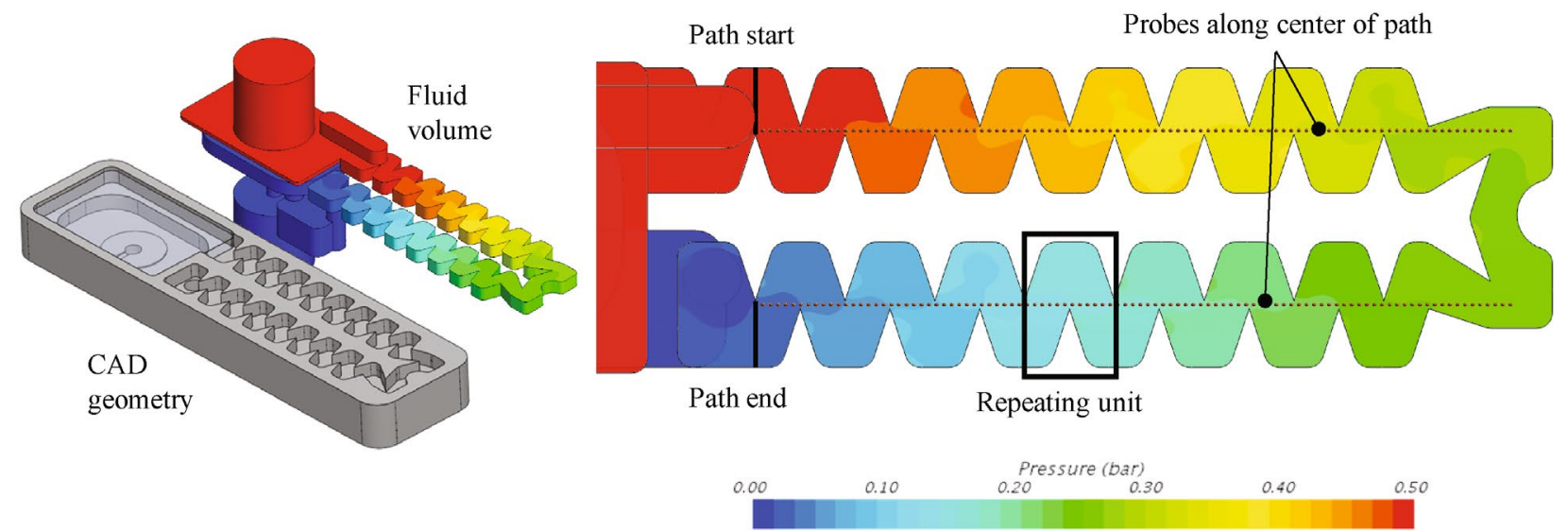

(a)

(b)

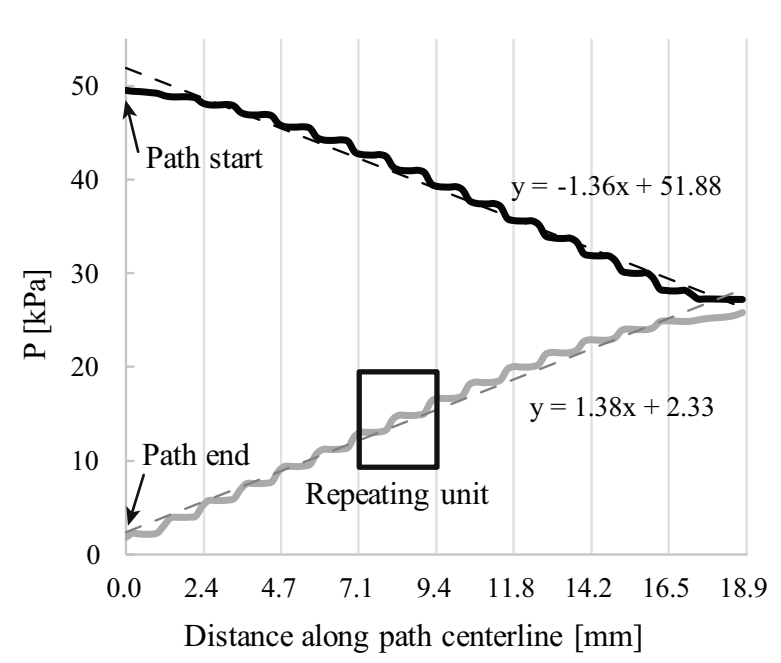

(c)

Fig. 12 Results of a CFD simulation for one commercial tortuous path. a Geometry of the solid emitter body and the extracted fluid volume. b The simulated pressure field along the tortuous path at $P_{\text {in }}=50 \mathrm{kPa}(0.5 \mathrm{bar})$ with a flow rate of $2.29 \mathrm{~L} / \mathrm{h}$. Dots indicate the location of probes where pressure readings were extracted. $\mathbf{c}$ Pressure along the centerline of the tortuous path plotted versus distance along the path. The first half of the path is plotted in black; the second half (after the U-turn) is plotted in gray. Linear curve fits (dashed lines) have similar slopes, indicating that pressure drop is approximately linear with each repeating unit 


\section{Experimental measurements of membrane deflection}

Method: Membranes from commercial drippers made by Jain Irrigation, Ltd., were tested in bending with a texture analyzer (Stable Microsystems TA.XT Plus, accuracy of \pm $0.5 \%$ for load cells, $\pm 0.1 \%$ for distance, $\pm 0.1 \%$ for speed). Each membrane was held in a custom fixture machined to replicate the geometry and boundary conditions of the membrane chamber in the commercial inline emitters. A load was applied at the center of the membrane with a $0.8-\mathrm{mm}$ diameter ball-end probe lubricated with WD-40 to minimize friction with the membrane. The texture analyzer measured the applied load, the distance moved by the probe (equal to the membrane deflection at the center), and the loading speed. Three membranes were tested, each at three different loading speeds $(0.1,0.25$, and $0.5 \mathrm{~mm} / \mathrm{s})$. The maximum deformation was limited to $1.1 \mathrm{~mm}$ - the maximum distance the membranes could deflect before reaching the lands in all emitters tested in this study.

Results: Normalized deflection versus loading curves are plotted in Fig. 11.

\section{CFD simulation of pressure drop in a tortuous path}

Method: A CFD simulation was used to validate the linearity of pressure drop with identical repeating units in a tortuous path. The geometry of the Jain Irrigation, Ltd., 2 $\mathrm{L} / \mathrm{h}$ PC emitter was used to extract the fluid volume and model the flow in STAR-CCM+ (Siemens Digital Industries Software 2018) (Fig. 12a). Boundary conditions were no slip along the walls, with the inlet at a uniform gauge pressure $P_{\text {in }}=50 \mathrm{kPa}(0.5 \mathrm{bar})$ and the outlet at zero gauge pressure. A polyhedral mesh with 502,776 cells was used. Pressure probes were set up along the length of the tortuous path, passing through the center of the gap between the teeth (Fig. 12b). The flow was simulated in steady state with the realizable $k$-epsilon turbulence model for the fluid, which has been used by Dazhuang et al. (2007) and is expected to have higher accuracy for rotating flows than the standard $k$-epsilon model. The $k$-epsilon turbulence models do not account for flow anisotropy, and Al-Muhammad et al. (2019) recommend the use of Reynolds Stress Models (RSM) in cases where detailed simulations of velocity profiles are needed. However, the purpose of the current analysis was solely to validate the trend of pressure drop with number of teeth, which has been seen with models ranging from standard $k$-epsilon (Yu et al. 2018) to RSM (Zhang et al. 2011a); hence, a $k$-epsilon model was deemed sufficient.

Results: Pressure is seen to be nearly linear after the initial regions at the start of the path and after the U-turn, where flow is developing hydro-dynamically (Fig. 12c). Hence, the pressure drop coefficient $K_{\text {path }}$ can be adjusted by a designer to a desired value by removing or adding repeating units from a tortuous path whose resistance has already been characterized.

Acknowledgements This study was supported by Jain Irrigation, Ltd., USAID Cooperative Agreement Number AID-OAA-A-16-00055 (BAA-MWSI-ME-2015), and the National Science Foundation Graduate Research Fellowship Program. The authors would like to thank Abhijit Joshi and Sachin Patil of Jain Irrigation, Ltd. for their advice and expertise on drip irrigation, Alyanna Villapando, Anthony Troupe and Elizabeth Brownell for help with lab prototyping and testing, Aditya Ghodgaonkar for feedback on the manuscript, and Susan Amrose for guidance on research methods and manuscript preparation.

Funding Open Access funding provided by the MIT Libraries.

\section{Declarations}

Conflict of interest The authors declare that they have no conflict of interest.

Open Access This article is licensed under a Creative Commons Attribution 4.0 International License, which permits use, sharing, adaptation, distribution and reproduction in any medium or format, as long as you give appropriate credit to the original author(s) and the source, provide a link to the Creative Commons licence, and indicate if changes were made. The images or other third party material in this article are included in the article's Creative Commons licence, unless indicated otherwise in a credit line to the material. If material is not included in the article's Creative Commons licence and your intended use is not permitted by statutory regulation or exceeds the permitted use, you will need to obtain permission directly from the copyright holder. To view a copy of this licence, visit http://creativecommons.org/licenses/by/4.0/.

\section{References}

Al-Amoud AI, Mattar MA, Ateia MI (2014) Impact of water temperature and structural parameters on the hydraulic labyrinth-channel emitter performance. Span J Agric Res 12(3):580-593. https://doi. org/10.5424/sjar/2014123-4990

Al-Muhammad J, Tomas S, Anselmet F (2016) Modeling a weak turbulent flow in a narrow and wavy channel: case of microirrigation. Irrig Sci 34(5):361-377. https://doi.org/10.1007/ s00271-016-0508-6

Al-Muhammad J, Tomas S, Ait-Mouheb N, Amielh M, Anselmet F (2018) Micro-PIV characterization of the flow in a milli-labyrinth-channel used in drip irrigation. Exp Fluids. https://doi.org/ 10.1007/s00348-018-2633-x

Al-Muhammad J, Anselmet F, Tomas S, Ait-mouheb N, Amielh M (2019) Experimental and numerical characterization of the vortex zones along a labyrinth milli-channel used in drip irrigation. Int J Heat Fluid Flow 80(108500):1-11

Bernstein L, Francois LE (1973) Comparisons of drip, furrow, and sprinkler irrigation. Soil Sci 115(1):73-86. https://doi.org/10. 1097/00010694-197301000-00010

Burney J, Woltering L, Burke M, Naylor R, Pasternak D (2010) Solarpowered drip irrigation enhances food security in the SudanoSahel. Proc Natl Acad Sci 107(5):1848-1853. https://doi.org/10. 1073/pnas.0909678107 
Celik HK, Karayel D, Caglayan N, Rennie AE, Akinci I (2011) Rapid prototyping and flow simulation applications in design of agricultural irrigation equipment: case study for a sample in-line drip emitter. Virtual Phys Prototyp 6(1):47-56. https://doi.org/10.1080/ 17452759.2010 .525215

Cetin O, Bilgel L (2002) Effects of different irrigation methods on shedding and yield of cotton. Agric Water Manag 54(1):1-15. https://doi.org/10.1016/S0378-3774(01)00138-X

ChinaDrip (2020) Drip tape and fitting. https://www.chinadrip.com/ drip-tape-and-fitting_c31

Cioncolini A, Scenini F, Duff J (2015) Micro-orifice single-phase liquid flow: pressure drop measurements and prediction. Exp Therm Fluid Sci 65:33-40. https://doi.org/10.1016/j.expthermfl usci.2015.03.005

Dazhuang Y, Peiling Y, Shumei R, Yunkai L, Tingwu X (2007) Numerical study on flow property in dentate path of drip emitters. $\mathrm{N} \mathrm{Z}$ J Agric Res 5007(September):705-712. https://doi.org/10.1080/ 00288230709510341

Edwards M, Jadallah M, Smith R (1985) Head losses in pipe fittings at low Reynolds numbers. Chem Eng Res Des 63(1):43-50

FAO (2011) The State of the World's land and water resources for Food and Agriculture - Managing systems at risk. Tech. rep., Food and Agriculture Organization of the United Nations, London. 978-1-84971-326-9

Feng J, Li Y, Wang W, Xue S (2018) Effect of optimization forms of flow path on emitter hydraulic and anti-clogging performance in drip irrigation system. Irrig Sci 36(1):37-47. https://doi.org/10. 1007/s00271-017-0561-9

Feng J, Li Y, Liu Z, Muhammad T, Wu R (2019) Composite clogging characteristics of emitters in drip irrigation systems. Irrig Sci 37(2):105-122. https://doi.org/10.1007/s00271-018-0605-9

Foley JA, Ramankutty N, Brauman KA, Cassidy ES, Gerber JS, Johnston M, Mueller ND, O'Connell C, Ray DK, West PC, Balzer C, Bennett EM, Carpenter SR, Hill J, Monfreda C, Polasky S, Rockström J, Sheehan J, Siebert S, Tilman D, Zaks DP (2011) Solutions for a cultivated planet. Nature 478(7369):337-342. https:// doi.org/10.1038/nature10452

Ghamarnia H, Arji I, Sepehri S, Norozpour S, Khodaei E (2011) Evaluation and comparison of drip and conventional irrigation methods on sugar beets in a semiarid region. J Irrig Drain Eng 138(1):90 97. https://doi.org/10.1061/(ASCE)IR.1943-4774.0000362

Hanson BR, Schwankl LJ, Schulbach KF, Pettygrove GS (1997) A comparison of furrow, surface drip, and subsurface drip irrigation on lettuce yield and applied water. Agric Water Manag 33(23):139-157. https://doi.org/10.1016/S0378-3774(96)01289-9

Ibragimov N, Evett SR, Esanbekov Y, Kamilov BS, Mirzaev L, Lamers JPA (2007) Water use efficiency of irrigated cotton in Uzbekistan under drip and furrow irrigation. Agric Water Manag 90(12):112-120. https://doi.org/10.1016/j.agwat.2007.01.016

ICID (2018) Annual report 2017-2018: Agricultural Water Management for Sustainable Rural Development. Tech. rep., International Commission on Irrigation and Drainage, New Delhi, India. https:// www.icid.org/ar_2017.pdf

Idelchik I (1996) Handbook of hydraulic resistance, 3rd edn. Begell House, New York

Jagermeyr J, Gerten D, Heinke J, Schaphoff S, Kummu M, Lucht W (2015) Water savings potentials of irrigation systems: global simulation of processes and linkages. Hydrol Earth Syst Sci 19(7):3073-3091. https://doi.org/10.5194/hess-19-3073-2015

Jain Irrigation Systems Ltd (2019) Jain turbo cascade PC, PCNL \& PCAS. https://www.jains.com/irrigation/emitting pipe/turbocscad e pc pcnl pcas.htm

Karmeli D (1977) Classification and flow regime analysis of drippers. J Agric Eng Res 22:165-173
Li Y, Yang P, Xu T, Ren S (2008) CFD and digital particle tracking to assess flow characteristics in the labyrinth flow path of a drip irrigation emitter. Irrig Sci 26:427-438. https://doi.org/10.1007/ s00271-008-0108-1

Maisiri N, Senzanje A, Rockstrom J, Twomlow SJ (2005) On farm evaluation of the effect of low cost drip irrigation on water and crop productivity compared to conventional surface irrigation system. Phys Chem Earth 30(11-16 SPEC. ISS):783-791. https://doi. org/10.1016/j.pce.2005.08.021

MathWorks Inc (2017) MATLAB R2017a

Mattar MA, Al-Amoud AI (2015) Artificial neural networks for estimating the hydraulic performance of labyrinth-channel emitters. Comput Electron Agric 114(April):189-201. https://doi.org/10. 1016/j.compag.2015.04.007

Mattar MA, Al-Amoud AI, Al-Othman AA, Elansary HO, Farah AHH (2019) Hydraulic performance of labyrinth-channel emitters: experimental study, ANN, and GEP modeling. Irrig Sci. https:// doi.org/10.1007/s00271-019-00647-1

Namara RE, Nagar RK, Upadhyay B (2007) Economics, adoption determinants, and impacts of micro-irrigation technologies: empirical results from India. Irrig Sci 25(3):283-297. https://doi. org/10.1007/s00271-007-0065-0

Narain J, Winter VAG (2019) A hybrid computational and analytical model of inline drip emitters. J Mech Des 141(7):071405. https:// doi.org/10.1115/1.4042613

Narayanamoorthy A (2004) Impact assessment of drip irrigation in India: the case of sugarcane. Dev Policy Rev 22(4):443-462. https://doi.org/10.1111/j.1467-7679.2004.00259.x

Netafim (2020) Heavywall driplines. https://www.netafimusa.com/ agriculture/products/product-offering/heavywall-driplines/

Nishimura T, Ohori Y, Kawamura Y (1983) Flow characteristics in channel with symmetric wavy wall for steady flow. Organized by Korean Inst of Chemical Engineers, pp 13-18

Pei Y, Li Y, Liu Y, Zhou B, Shi Z, Jiang Y (2014) Eight emitters clogging characteristics and its suitability under on-site reclaimed water drip irrigation. Irrig Sci 32(2):141-157. https://doi.org/10. 1007/s00271-013-0420-2

Philipova N, Nikolov N, Pichurov G, Markov D (2011a) Regression equations of pressure losses of rectangular labyrinth channel and bi-objective optimization. Comptes rendus de l'Academie bulgare des Sciences 64(12):1749-1756

Philipova N, Nikolov N, Stoimenova E, Pichurov G, Markov D (2011b) Mathematical modeling of drip emitter discharge of triangular labyrinth channel. Comptes rendus de l'Academie bulgare des Sciences 64(1)

Phocaides A (2007) Handbook on pressurized irrigation techniques. Tech. rep., Food and Agriculture Organization of the United Nations (FAO), Rome, Italy, https://doi.org/10.1016/07351097(89)90316-1

Postel S, Polak P, Gonzales F, Keller J (2001) Drip irrigation for small farmers: a new initiative to alleviate hunger and poverty. Water Int 26(1):3-13. https://doi.org/10.1080/02508060108686882

Rainbird (2020) Drip irrigation. https://www.rainbird.com/agriculture/ products/drip-irrigation

Shamshery P, Winter AG (2018) Shape and form optimization of online pressure-compensating drip emitters to achieve lower activation pressure. J Mech Des 140(March):035001-035001. https:// doi.org/10.1115/1.4038211

Shamshery P, Wang RQ, Tran DV, Winter AG (2017) Modeling the future of irrigation: a parametric description of pressure compensating drip irrigation emitter performance. PLoS One. https://doi. org/10.1371/journal.pone.0175241

Siemens Digital Industries Software (2018) Simcenter STAR-CCM+, version 13.04 
Sokol J, Amrose S, Nangia V, Talozi S, Brownell E, Montanaro G, Naser KA, Mustafa KB, Bahri A, Bouazzama B, Bouizgaren A, Mazahrih N, Moussadek R, Sikaoui L, Winter AG (2019) Energy reduction and uniformity of low-pressure online drip irrigation emitters in field tests. Water (Switzerland). https://doi.org/10. 3390/w11061195

Srivastava RC, Verma HC, Mohaty S, Pattnaik SK (2003) Investment decision model for drip irrigation system. Irrig Sci 22:79-85. https://doi.org/10.1007/s00271-003-0072-8

Szilard R (2003) Theories and applications of plate analysis. Wiley, Hoboken

Tian W (2013) A review of sensitivity analysis methods in building energy analysis. Renew Sustain Energy Rev 20:411-419. https:// doi.org/10.1016/j.rser.2012.12.014

Venot JP, Kuper M, Zwarteveen M (2017) Drip irrigation for agriculture: untold stories of efficiency, innovation and development. Taylor and Francis, Routledge, London

Ventsel E, Krauthammer T (2001) Thin plates and shells. Marcel Dekker Inc, New York. https://doi.org/10.1201/9780203908723

Wang L, Wei Z, Zhou X, Yuan W (2012a) Rapid stereotype of cylindrical drip emitter based on computational fluid dynamics and rapid prototyping manufacturing. Appl Mech Mater 190-191:390-394. https://doi.org/10.4028/www.scientific.net/AMM.190-191.390

Wang W, Bralts V, Wang J (2012b) A hydraulic analysis of an online pressure compensating emitter using CFD-CSD technology. In: 2012 ASABE annual international meeting. https://doi.org/10. $13031 / 2013.41926$

Wei Z (2013) The step-by-step CFD design method of pressure-compensating emitter. Eng Sci 11(1):62-67

Wei Q, Shi Y, Dong W, Lu G, Huang S (2006) Study on hydraulic performance of drip emitters by computational fluid dynamics. Agric Water Manag 84(1-2):130-136. https://doi.org/10.1016/j. agwat.2006.01.016

Woltering L, Ibrahim A, Pasternak D, Ndjeunga J (2011) The economics of low pressure drip irrigation and hand watering for vegetable production in the Sahel. Agric Water Manag 99(1):67-73. https:// doi.org/10.1016/j.agwat.2011.07.017
Wu D, Li Y, Hs Liu, Pl Yang, Hs Sun, Yz Liu (2013) Simulation of the flow characteristics of a drip irrigation emitter with large eddy methods. Math Comput Model 58(3-4):497-506. https://doi.org/ 10.1016/j.mcm.2011.10.074

Yu L, Li N, Long J, Liu X, Yang Q (2018) The mechanism of emitter clogging analyzed by CFD-DEM simulation and PTV experiment. Adv Mech Eng 10(1):1-10. https://doi.org/10.1177/1687814017 743025

Zhang J, Zhao W, Tang Y, Lu B (2010) Anti-clogging performance evaluation and parameterized design of emitters with labyrinth channels. Comput Electron Agric 74(1):59-65. https://doi.org/10. 1016/j.compag.2010.06.005

Zhang J, Zhao W, Lu B (2011a) New method of hydraulic performance evaluation on emitters with labyrinth channels. J Irrig Drain Eng 137(12):811-815. https://doi.org/10.1061/(ASCE)IR.1943-4774. 0000365

Zhang J, Zhao W, Tang Y, Lu B (2011b) Structural optimization of labyrinth-channel emitters based on hydraulic and anti-clogging performances. Irrig Sci 29(5):351-357. https://doi.org/10.1007/ s00271-010-0242-4

Zhangzhong L, Yang P, Ren S, Liu Y, Li Y (2015) Flow characteristics and pressure-compensating mechanism of non-pressure-compensating drip irrigation emitters. Irrig Drain 64(5):637-646. https:// doi.org/10.1002/ird.1929

Zhao W, Zhang J, Tang Y, Wei Z, Lu B (2009) Research on transitional flow characteristics of labyrinth channel emitter. IFIP Int Feder Inf Process 294:881-890. https://doi.org/10.1007/ 978-1-4419-0211-5-11

Publisher's Note Springer Nature remains neutral with regard to jurisdictional claims in published maps and institutional affiliations. 